\title{
Identification of molecular species of simple lipids by normal phase liquid chromatography-positive electrospray tandem mass spectrometry, and application of developed methods in comprehensive analysis of low erucic acid rapeseed oil lipids
}

\author{
P.J. Kalo ${ }^{\text {a,* }}$, V. Ollilainen ${ }^{\text {a }}$, J.M. Rocha ${ }^{\text {a,b }}$, F.X. Malcata ${ }^{\text {b }}$ \\ ${ }^{a}$ Department of Applied Chemistry and Microbiology, Latokartanonkaari 11, University of Helsinki, \\ Helsinki FIN-00014, Finland \\ ${ }^{\mathrm{b}}$ Escola Superior de Biotecnologia, Universidade Católica Portuguesa, Rua Dr. António Bernardino de Almeida, \\ P-4200-072 Porto, Portugal
}

Keywords: Mono-, Di- and Triacylglycerol; Sterol; Free fatty acid; Normal phase liquid chromatography - Positive electrospray ionization tandem mass spectrometry; Low erucic acid rapeseed oil

\begin{abstract}
Mono-, di- and triacylglycerol (MAG, DAG, TAG), sterol ester (SE), free sterol (S) and free fatty acid (FFA) standards were analyzed in the presence of ammonium ions and ammonia by flow injection $\mathrm{MS}^{2}$ and $\mathrm{MS}^{3}$, and by normal phase-liquid chromatography (NP-LC) MS ${ }^{2}$ positive electrospray ionization (ESI) mass spectrometry (MS). The MS data recorded for ammonium adducts $\left(\left[M+\mathrm{NH}_{4}\right]^{+}\right)$of TAGs, DAGs, and MAGs were consistent with stepwise fragmentation mechanisms. In the first step, ammonium ion in $\left[M+\mathrm{NH}_{4}\right]^{+}$donates proton to acylglycerol and ammonia is released. In the second step, FFA is cleaved from protonated TAG, water from protonated 1,3-DAG and MAG, both FFA and water from protonated 1,2-DAG, hence leading to formation of [DAG] $]^{+}$ion from TAG and 1,3-DAG, [DAG] ${ }^{+}$and $[\mathrm{MAG}]^{+}$ions from 1,2-DAG, and $[\mathrm{MAG}]^{+}$ion from MAG. In the third step, $[\mathrm{DAG}]^{+}$ion of TAG is fragmented to yield $[\text {Acyl }]^{+},[\text {Acyl }+74]^{+},[\mathrm{DAG}-74]^{+}$ions, $[\mathrm{DAG}]$ ion of 1,3-DAG to [Acyl] $]^{+}$ions, and $[\mathrm{MAG}]^{+}$ion of MAG to protonated FAs, which are decomposed to water and [Acyl] $]^{+}$ions in the fourth step. A stepwise mechanism for fragmentation of FFA was also evident from $\mathrm{MS}^{2}$ and $\mathrm{MS}^{3}$ data.

Molecular species of low erucic acid rapeseed oil simple lipids were identified from characteristic ions produced in the NP-LC-ESI-MS ${ }^{2}$ of $\left[M+\mathrm{NH}_{4}\right]^{+}$ions. The percentage composition of the molecular species of each lipid class was calculated from integrated extracted ion chromatograms of $\left[\left(M+\mathrm{NH}_{4}\right)\right]^{+}$ions of SE, TAG, MAG, and FFA, of the sum of $\left[\left(M+\mathrm{NH}_{4}\right)\right]^{+}$and $\left[\left(M+\mathrm{NH}_{4}\right)-\mathrm{NH}_{3}-\mathrm{H}_{2} \mathrm{O}\right]^{+}$ions of both regioisomers of DAGs, and of sterol fragment ions of $\mathrm{S}$.
\end{abstract}

\footnotetext{
Abbreviations: $\mathrm{ACN}: \mathrm{DB}$, the number of acyl group carbons:the number of double bonds; $\mathrm{APCI}$, atmospheric pressure chemical ionization; $\mathrm{CE}$, cholesterol ester; CI, chemical ionization; CID, collision induced decay; DAG, diacylglycerol; EI, electron impact; EIC, extracted ion chromatogram; ESI, electrospray ionization; FA, fatty acid; FFA, free fatty acid; FI, flow injection; FT, Fourier transform; GC, gas liquid chromatography; HPLC, high performance liquid chromatography; LC, liquid chromatography; ICR, ion cyclotron resonance; MAG, monoacylglycerol; MALDI, matrix-assisted laser desorption ionization; MS, mass spectrum/spectra; $\mathrm{MS}^{2}$, MS/MS tandem mass spectrum/spectra; $\mathrm{MS}^{3}$, MS/MS/MS tandem mass spectrum/spectra; $\mathrm{m} / \mathrm{z}$, mass to charge ratio; NI, negative ion; NP, normal phase; rac, racemic; RP, reversed phase; SE, sterol ester; $s n$, stereospecifically numbered; S, free sterol; TAG, triacylglycerol

* Corresponding author. Tel.: +358 400 101162; fax: +358 919158475.

E-mailaddresses: paavo.kalo@ helsinki.fi (P.J. Kalo), velimatti.ollilainen@helsinki.fi (V. Ollilainen), jmrocha@mail.esb.ucp.pt (J.M. Rocha), xmalcata@esb.ucp.pt (F.X. Malcata).
} 


\section{Introduction}

In the present study, we studied the identification of molecular species of simple lipids (mono-, di- and triacylglycerol (MAG, DAG, TAG), sterol ester (SE), free sterol (S) and free fatty acid (FFA)), and the fragmentation paths of their ammonium adducts in collision induced decay (CID) in flow injection and normal phase-liquid chromatography (NP-LC) positive electrospray ionization (ESI) mass spectrometry (MS).

Simple lipids, i.e., lipids, which yield in saponification at most two types of primary hydrolysis products [1], are important lipid components. In nutrition, the major simple lipids, TAGs, play an important role as energy source and storage. The rest of simple lipid classes, i.e., DAGs, MAGs, FFAs, Ss and SEs, are present in fats and oils in minor amounts, but have significant nutritional, metabolic and technological importance.

Duffin et al. studied CID of ammonium adducts of MAGs, DAGs and TAGs produced by ESI [2]. The CID of ammonium adducts of TAGs has been further considered by several investigators using ESI ionization [3-9]. ESI tandem mass spectrometry of sodium and lithium adducts of TAGs has been applied for structural analysis as well [3,10-12]. Han et al. used intrasource lipid class-selective ESI and neutral loss and precursor ion scanning in identification and quantification of molecular species in FFA, TAG, and several subclasses of phospholipids [11]. Recently, vegetable oil DAGs and TAGs have been characterized by positive ESI Fourier transform (FT) ion cyclotron resonance (ICR) MS [13]. Furthermore, atmospheric pressure chemical ionization (APCI) LC-MS [14-16] as well as matrixassisted laser desorption ionization (MALDI) MS [17] have been applied in the characterization of DAGs. To our knowledge, besides the publication of Duffin et al. [2] no other studies using ESI-MS in the analysis of MAGs have been published. Precursor ion tandem MS in positive ion mode of ESI ionized cholesterol esters [18] and plant SEs [19] has been used for identification and quantification. Furthermore, electron impact (EI) and chemical ionization (CI) gas chromatography (GC) MS [20], and EI and negative ion (NI) CI-GC-MS [21], has been applied in the characterization of sterol fatty acid esters, whereas LC-ESIMS/MS in positive and negative ion modes has been used in the study of sterol ferulates [22]. FFAs have been characterized by NI-ESI tandem MS [23] and by two-dimensional ESI-MS [11], hydroxy-FAs by NI-ESI tandem MS [24], and dilithiated adducts of long-chain unsaturated FFAs have been analyzed by ESI-MS with low energy collisionally activated dissociation with the aim to locate the double bond positions [25]. Reversed phase (RP) LC-ESI-MS and -MS/MS, in the negative ion mode, has been applied for characterization and quantification of FFAs, as well as in the study of charge-remote fragmentation mechanism [26,27].

Rapeseed oil TAGs have been analyzed by GC-CI-MS [28], NI-CI-MS/MS [29], APCI-MS [30,31,15], and ESI-FT-ICRMS [13]. DAGs in the same matrix have been identified by APCI-MS [15,30], and the relative abundances of ACN:DB DAG classes and those of FFAs have been determined by either positive or negative ESI-FT-ICR-MS, respectively [13]. Precursor ion positive ESI-MS/MS has been applied to the determina- tion of relative ratios of esterified Ss and esterified FAs in SEs of low erucic acid rapeseed oil [19].

The objective of present study was to investigate all simple lipid classes (TAG, DAG, MAG, SE, S, and FFA) by positive electrospray ionization, in the presence of ammonium ions and ammonia, and NP-LC-ESI-MS ${ }^{2}$ and flow injection-ESI-MS ${ }^{2}$ and $-\mathrm{MS}^{3}$ of standard compounds. Our aim was to conclude the fragmentation mechanisms from tandem MS data. In order to demonstrate the applicability of the methods developed, simple lipids of low erucic acid rapeseed oil were identified from NP-LC-ESI-MS ${ }^{2}$ and the percentage composition of molecular species of each lipid class was determined.

\section{Experimental}

Materials

Standards

Cholesterol ester standards, 1-lauroyl-2-oleoyl-3-palmitoylrac-glycerol, 1,3-dihexadecanoylglycerol, monoacid TAG and DAG standards, and MAG and FFA standards were purchased from $\mathrm{Nu}$ Chek Prep (Elysian, MN, USA), Sigma (St. Louis, MO, USA) and Fluka (Buchs, Switzerland), and 1-monopalmitin, 1mono-olein, and plant sterol mixture from Larodan Fine Chemicals (Malmo, Sweden).

Solvents

All solvents were purchased from Rathburn, UK and were of HPLC grade.

Low erucic acid rapeseed oil was purchased from local store.

Liquid chromatography...electrospray ionization mass spectrometry (LC...ESI-MS)

High performance liquid chromatography (HPLC)

Lipid standards and vegetable oil solutions were analyzed by normal phase HPLC using two Phenomenex Luna $3 \mu \mathrm{m}$ silica columns $(100 \mathrm{~mm} \times 2.0 \mathrm{~mm})$ and a guard column $(4 \mathrm{~mm} \times 2.0 \mathrm{~mm})$ in series. A multistep binary gradient of hexane (A) and hexane-methyl-tert-butyl ether-acetic acid (B) was employed at flow rate of $0.1 \mathrm{ml} / \mathrm{min}$ (Table 1).

\section{HPLC with electrospray ionization mass spectrometry (LC-ESI.Ms)}

An ion-trap Bruker Esquire LC-MS (Bruker Daltonic, Bremen, Germany) was operated in positive electrospray ionization mode. Acquisition parameters in the method for SE, TAG, and DAG and (in that for FFA, S, and DAG) were: capillary voltage $3000 \mathrm{~V}(3000 \mathrm{~V})$, capillary exit offset $30 \mathrm{~V}(30 \mathrm{~V})$, skimmer potential $20 \mathrm{~V}(20 \mathrm{~V})$, and trap drive value of 70 (40). Full scan ESI mass spectra were recorded using a scan range of 15-1200 $(50-500) \mathrm{m} / \mathrm{z}$ and summation of 15 spectra. Nebulizer (nitrogen) flow was $81 / \mathrm{min}$ and drying temperature $300^{\circ} \mathrm{C}$. Auto-MS/MS spectra for two most intense ions eluting concurrently were recorded using helium (99.996\%) as the collision gas. In addition to auto-MS/MS, time windows for isolating and fragmentation of the ions for minor components of low erucic acid rapeseed oil 
Table 1

Multistage binary gradient system in the NP-HPLC

\begin{tabular}{ccl}
\hline Time $(\mathrm{min})$ & $\% \mathrm{~B}$ (by vol.) & Flow $(\mathrm{ml} / \mathrm{min})$ \\
\hline 0 & 0.0 & 0.1 \\
2 & 7.5 & 0.1 \\
16 & 7.5 & 0.1 \\
22 & 9 & 0.1 \\
30 & 9 & 0.1 \\
31 & 45 & 0.1 \\
52 & 45 & 0.1 \\
62 & 90 & 0.1 \\
63 & 99 & 0.1 \\
64 & 99 & 0.5 \\
75 & 99 & 0.5 \\
76 & 0.0 & 0.5 \\
80 & 0.0 & 0.5 \\
81 & 0.0 & 0.1 \\
130 & 0.0 & 0.1
\end{tabular}

Solvent A: hexane; solvent B: hexane/methyl-tert-butyl ether/acetic acid $80: 20: 1$, by vol.

were used. The reagent solvent, chloroform/methanol/ammonia water $(25 \%)$ 20:10:3 (v/v), was pumped with a flow rate of $6.0 \mathrm{ml} / \mathrm{min}$ via a 1:100 split device to effluent flow [7].

Flow injection electrospray ionization mass spectrometry (FI-ESI.MS)

Chloroform solution of lipid standard was pumped using syringe pump (Cole Parmer 74900 series), at a flow rate of $500 \mu \mathrm{l} / \mathrm{h}$, to the eluent flow (Table 1 ). The composition of eluent corresponded to that of the LC-MS efluent, in which the compound concerned was eluted. The mass spectrometric conditions were the same used in the LC-MS for the respective lipid class.

\section{Calibration}

The amount/area ratios were determined for ammonium adducts of the following mixtures: monoacid TAGs 54:0, $54: 3,54: 6,51: 0,48: 0,48: 3,42: 0,36: 0$; monoacid DAGs $16: 0,24: 0,24: 2,32: 0,32: 2,36: 0,36: 2,36: 4,38: 0,38: 2$; MAGs 16:0, 18:0, 18:1, 18:2, 18:3; FFAs 16:0, 18:0, 18:1, 18:2, 18:3; Ss brassica-, campe-, stigma-, and sitosterol. The extracted ion chromatograms (EIC) of ammonium adducts for the standard compounds in each standard mixture were extracted from total ion current data of LC-ESI-MS, and duly integrated. The amount/area ratio was calculated for each standard compound. For calculation of amount/area ratios for the TAGs with $\mathrm{ACN}$ :DB not present in standard mixtures, plots of amount/normalized area versus ACN were produced for saturated TAGs (regression equation: $\left.y=0.0053 x^{2}-0.3656 x+6.3881, R^{2}=0.877, n=20\right)$ and ACN 54 TAGs with different unsaturation $(y=-0.2086 x+1.8768$, $\left.R^{2}=0.906, n=9\right)$. Respective plots were produced for saturated DAGs $\left(y=0.0744 x-1.2635, R^{2}=0.941, n=10\right)$, diene DAGs (best fit: $y=0.0517 x-0.9422, R^{2}=1.000, n=8$ ), and for ACN 36 DAGs with varying degrees of unsaturation $\left(y=-0.2353 x+1.4924, R^{2}=0.960, n=6\right)$. For $\mathrm{SE}$ with different unsaturation the correction factor of the corresponding $\mathrm{CE}$ was used [19].

\section{Results}

\section{Triacylglycerols (TAGs)}

Under the experimental conditions used, TAGs formed only ammonium adducts without fragmentation, as observed elsewhere [7]. In the $\mathrm{MS}^{2}$ of unsaturated monoacid TAGs, abundant

Table 2

Characteristic ions in full scan and product ion tandem mass spectra of ammonium adducts of monoacid triacylglycerols recorded in flow injection (FI) and liquid chromatography mass spectrometry (LC-MS) modes

\begin{tabular}{|c|c|c|c|c|c|c|c|}
\hline Standard & MS type & {$\left[M+\mathrm{NH}_{4}\right]^{+}, \mathbf{1}^{\mathrm{a}}$} & $\begin{array}{l}{\left[\left(M+\mathrm{NH}_{4}\right)-\right.} \\
\left.\mathrm{NH}_{3}\right]^{+}, \mathbf{2 a}, \mathbf{2} \mathbf{b}^{\mathrm{a}}\end{array}$ & $\begin{array}{l}{\left[\left(M+\mathrm{NH}_{4}\right)-\mathrm{NH}_{3}-\right.} \\
\left.\mathrm{H}_{2} \mathrm{O}\right]^{+}\end{array}$ & $\begin{array}{l}{\left[\left(M+\mathrm{NH}_{4}\right)-\mathrm{NH}_{3}-\right.} \\
\mathrm{FA}]^{+}, \mathbf{3 a}, \mathbf{3} \mathbf{b}^{\mathrm{a}}\end{array}$ & Acyl & Other \\
\hline \multirow[t]{3}{*}{$\begin{array}{l}\text { TAG 54:3 } \\
\text { FI }\end{array}$} & MS & $903(100)^{\mathrm{b}}$ & & & & & \\
\hline & $\begin{array}{l}\text { MS2 } 903 \\
\text { MS3 } 903 \rightarrow 886\end{array}$ & & $886(7)$ & $868(13)$ & $\begin{array}{l}603(100) \\
603(100)\end{array}$ & & \\
\hline & MS3 $903 \rightarrow 603$ & & & & & $265(85)$ & $\begin{array}{l}339(100)^{\mathrm{c}}, \\
529(20)^{\mathrm{d}}\end{array}$ \\
\hline $\begin{array}{l}\text { TAG 54:3 } \\
\text { LC-MS }\end{array}$ & MS2 903 & & $886(7)$ & & $603(100)$ & & \\
\hline $\begin{array}{l}\text { TAG } 54: 6 \\
\text { FI }\end{array}$ & MS2 897 & & $880(91)$ & & $600(100)$ & & \\
\hline & MS3 $897 \rightarrow 880$ & & & $862(20)$ & $600(100)$ & & \\
\hline TAG 54:6 LC-MS & MS2 897 & & $880(76)$ & $862(8)$ & $600(100)$ & & \\
\hline $\begin{array}{l}\text { TAG } 48: 0 \\
\text { LC-MS }\end{array}$ & MS2 825 & & & & $552(100)$ & & \\
\hline $\begin{array}{l}\text { TAG } 48: 3 \\
\text { LC-MS }\end{array}$ & MS2 819 & & $802(3)$ & & $548(100)$ & & \\
\hline
\end{tabular}

\footnotetext{
${ }^{\text {a }}$ Refer to the structure proposed in Scheme 1 .

b $\mathrm{m} / \mathrm{z}$ (abundance \%).

c $[\text { Acyl + 74 }]^{+}$.

d $\left[\left(M+\mathrm{NH}_{4}\right)-\mathrm{NH}_{3}-\mathrm{FA}-74\right]^{+}$.
} 


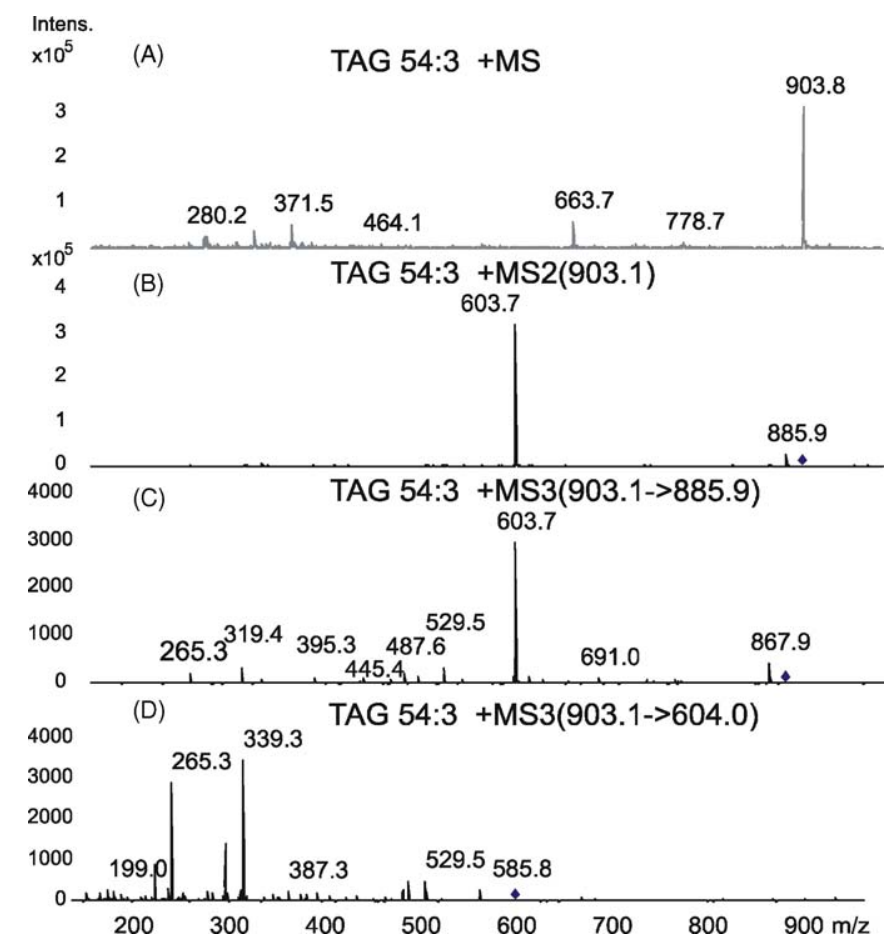

Fig. 1. Mass spectra of trioleoylglycerol recorded in the flow injection mode. (A) Full scan mass spectrum of ammonium adduct. (B) Tandem mass spectrum $\left(\mathrm{MS}^{2}\right.$ ) of ammonium adduct. (C) Mass spectrum of ion with $\mathrm{m} / \mathrm{z} 886$ produced in collision induced decay of ammonium adduct $=\mathrm{MS}^{3}(903 \rightarrow 886)$. (D) Mass spectrum of ion with $m / z 604$ produced in collision induced decay of ammonium adduct $=$ MS $^{3}(903 \rightarrow 604)$.

DAG ions $\left[\left(M+\mathrm{NH}_{4}\right)-\mathrm{NH}_{3}-\mathrm{FA}\right]^{+}$and $\left[\left(M+\mathrm{NH}_{4}\right)-\mathrm{NH}_{3}\right]^{+}$ ions with varying intensity were found (Table 2, Fig. 1B). The $\mathrm{MS}^{2}$ of triolein and tripalmitolein ammonium adducts showed low intensity ions $m / z$ 886, and 802 formed by loss of ammonia and intense ions $m / z 603$ and 548, formed by cleavage of oleic acid and palmitoleic acid, respectively, along with ammonia (Table 2). Whereas, the $\mathrm{MS}^{2}$ of trilinolein ammonium adduct showed abundant ions $m / z 880$ (76\%), and $600(100 \%)$ and a low intensity ion $\mathrm{m} / \mathrm{z} 862(8 \%)$, formed by cleavage of ammonia, linoleic acid along with ammonia, and ammonia and water, respectively. In the $\mathrm{MS}^{2}$ of saturated TAG (tripalmitin) these ions were not observed and DAG ion $\left[\left(M+\mathrm{NH}_{4}\right)-\mathrm{NH}_{3}-\mathrm{FA}\right]^{+}$ was the only product in CID. FI-MS ${ }^{3}\left[M+\mathrm{NH}_{4}\right]^{+} \rightarrow[(M+$ $\left.\left.\mathrm{NH}_{4}\right)-\mathrm{NH}_{3}\right]^{+}$yielded $\left[\left(M+\mathrm{NH}_{4}\right)-\mathrm{NH}_{3}-\mathrm{H}_{2} \mathrm{O}\right]^{+}$and $\left[\left(M+\mathrm{NH}_{4}\right)-\mathrm{NH}_{3}-\mathrm{FA}\right]^{+}$ions, with medium and high abundance, respectively (Table 2, Fig. 1C). FI-MS ${ }^{3}\left[M+\mathrm{NH}_{4}\right]^{+} \rightarrow$ $\left[\left(M+\mathrm{NH}_{4}\right)-\mathrm{NH}_{3}-\mathrm{H}_{2} \mathrm{O}\right]^{+}$showed abundant $[\mathrm{Acyl}]^{+},[\mathrm{Acyl}+$ $74]^{+}$, and medium abundance $\left[\left(M+\mathrm{NH}_{4}\right)-\mathrm{NH}_{3}-\mathrm{FA}-74\right]^{+}$ ions (Table 2, Fig. 1D).

These data of unsaturated TAGs (Table 2, Fig. 1) indicate a stepwise fragmentation mechanism (Scheme 1). In the first step (1) of this mechanism: the ammonium ion of $\left[M+\mathrm{NH}_{4}\right]^{+}$ donates a proton to one of the ester carbonyls of triacylglycerol $\mathbf{1}$, ammonia is released, and the onium ions $\mathbf{2} \mathbf{a}$ and $\mathbf{2 b}$ are formed. The relative abundances of ion $\mathbf{2 a}$ or $\mathbf{2} \mathbf{b}$ vary from a few percent points up to $70-90 \%$ in tandem MS of triene and hexaene TAGs, respectively. In the second step (2) of the mechanism, carboxylic acid is released from the $s n$-1(3)- or $s n$-2-position of onium ions $\mathbf{2} \mathbf{a}$ or $\mathbf{2} \mathbf{b}$ and the carbocation formed primarily is expected to be isomerized to [DAG] ${ }^{+}$ion $\mathbf{3 a}$ or $\mathbf{3 b}$, respectively, which is stabilized by five- or six-membered rings. This became evident from the FI-MS ${ }^{3}\left[M+\mathrm{NH}_{4}\right]^{+} \mathbf{1} \rightarrow\left[\left(M+\mathrm{NH}_{4}\right)-\mathrm{NH}_{3}\right]^{+}$ 2 of triolein and trilinolein. Furthermore, in the $\mathrm{MS}^{2}$ spectra of all saturated and unsaturated TAG, $[\mathrm{DAG}]^{+}$ion $\mathbf{3}$ is the base peak. In the third step (3) of the mechanism, characteristic $[\text { Acyl }]^{+},[\text {Acyl }+74]^{+} \mathbf{4 a}$, and $\left[\left(M+\mathrm{NH}_{4}\right)-\mathrm{NH}_{3}-\mathrm{FA}-74\right]^{+}$ $\mathbf{4 b}$ ions are formed, as observed in the FI-MS ${ }^{3}\left[M+\mathrm{NH}_{4}\right]^{+} \mathbf{1} \rightarrow$ $\left[\left(M+\mathrm{NH}_{4}\right)-\mathrm{NH}_{3}-\mathrm{FA}\right]^{+} \mathbf{3}$ of triolein.

\section{Diacylglycerols (DAGs)}

In the FI-MS of 1,3-dihexadecanoylglycerol were shown an intense $\left[M+\mathrm{NH}_{4}-\mathrm{NH}_{3}-\mathrm{H}_{2} \mathrm{O}\right]^{+}$ion with $\mathrm{m} / z 552(100 \%)$, and a less intense ion $\left[M+\mathrm{NH}_{4}\right]^{+}, \mathrm{m} / z 587$ (25\%) (Table 3, Fig. 2A). The $\mathrm{MS}^{2}$ of $\left[M+\mathrm{NH}_{4}\right]^{+}$showed DAG ion $\left[M+\mathrm{NH}_{4}\right.$ $\left.-\mathrm{NH}_{3}-\mathrm{H}_{2} \mathrm{O}\right]^{+}$with $m / 2552$ solely (Table 3, Fig. 2B). The FI-MS ${ }^{3}\left[M+\mathrm{NH}_{4}\right]^{+} \rightarrow\left[M+\mathrm{NH}_{4}-\mathrm{NH}_{3}-\mathrm{H}_{2} \mathrm{O}\right]^{+}$consisted of an intense [Acyl] ${ }^{+}$ion with $\mathrm{m} / \mathrm{z} 239$, as well as low intensity ions [Acid 16:0+ ] $^{+}$with $\mathrm{m} / z 257$ and [Acyl 16:0- $\left.\mathrm{H}_{2} \mathrm{O}\right]^{+}$ with $m / z 211$ (Table 3, Fig. 2C). In the ESI LC-MS of 1,3dihexadecanoylglycerol, the ion chromatogram with $\mathrm{m} / \mathrm{z}$ 587, extracted by computer from total ion current data, showed an intense peak at $48.1 \mathrm{~min}$ and a weak peak at $51.9 \mathrm{~min}$. The MS recorded at 48.1 min consisted of an intense DAG ion $\left[M+\mathrm{NH}_{4}-\mathrm{NH}_{3}-\mathrm{H}_{2} \mathrm{O}\right]^{+}$with $\mathrm{m} / z 552(100 \%)$ and a less intense $\left[M+\mathrm{NH}_{4}\right]^{+}$ion with $\mathrm{m} / z 587(25 \%)$ (Table 3). In the CID of $\left[M+\mathrm{NH}_{4}\right]^{+}$ion with $m / 2587$, the ion $\left[M+\mathrm{NH}_{4}-\mathrm{NH}_{3}\right]^{+}$ with $\mathrm{m} / z 569(100 \%)$, was formed by cleavage of ammonia (Table 3), and in the CID of $\left[M+\mathrm{NH}_{4}-\mathrm{NH}_{3}-\mathrm{H}_{2} \mathrm{O}\right]^{+}$ion with $\mathrm{m} / \mathrm{z}$ 552, the [Acyl 16:0] ${ }^{+}$ion with $\mathrm{m} / \mathrm{z} 239(100 \%)$, and the [Acyl $\left.16: 0-\mathrm{H}_{2} \mathrm{O}\right]^{+}$ion with $\mathrm{m} / \mathrm{z}, 221(55 \%)$, were formed (Table 3).

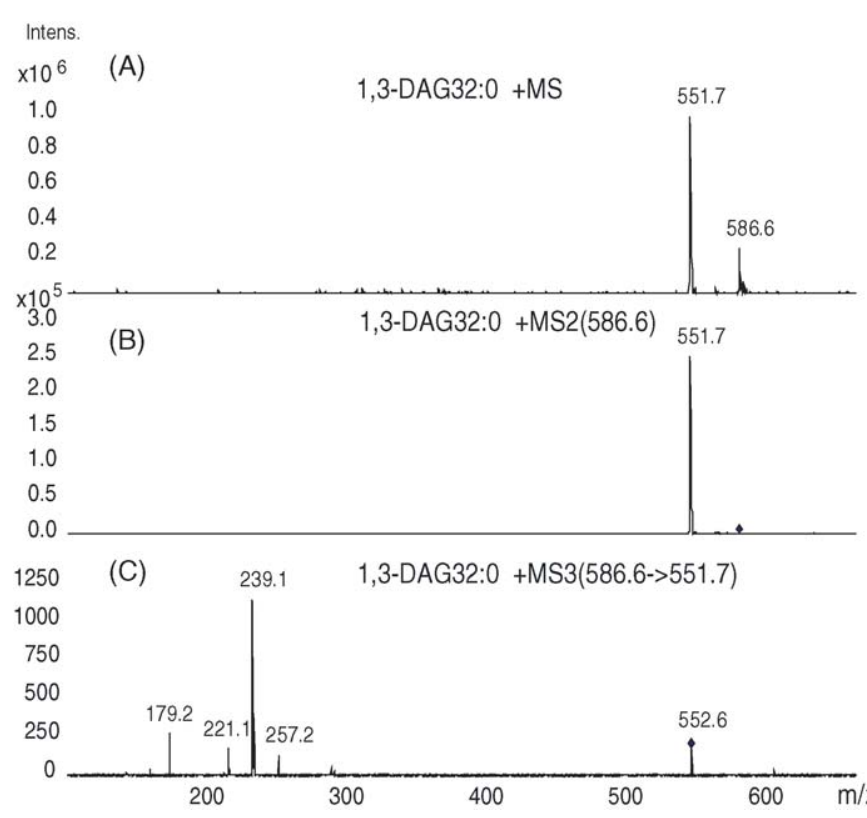

Fig. 2. Mass spectra of 1,3-dihexadecanoylglycerol recorded in the flow injection mode. (A) Full scan mass spectrum of ammonium adduct. (B) Tandem mass spectrum $\left(\mathrm{MS}^{2}\right.$ ) of ammonium adduct. (C) Mass spectrum of ion with $m / z 552$ produced in collision induced decay of ammonium adduct $=\mathrm{MS}^{3}(586 \rightarrow 552)$. 


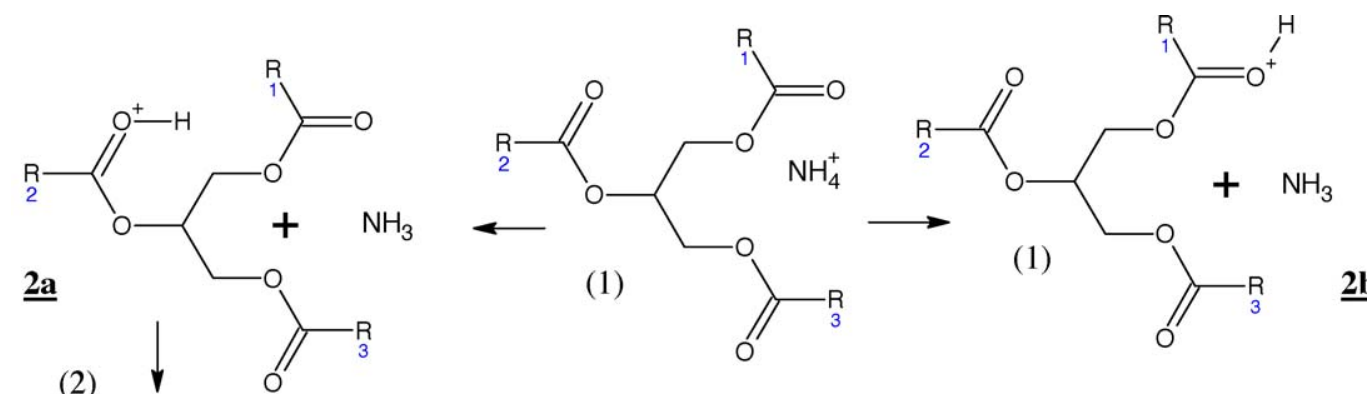

(2)

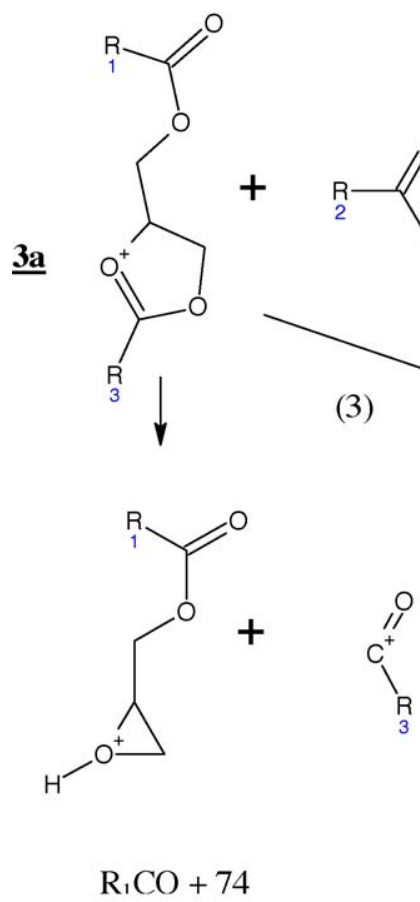

$\underline{4 a}$ $\underline{1}$

(2)

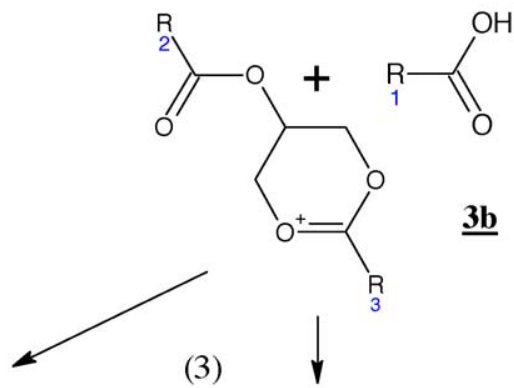

$\left[\mathrm{M}+\mathrm{NH}_{4}-\mathrm{NH}_{3}-\mathrm{FA}-74\right]^{+}$

$\underline{4 b}$

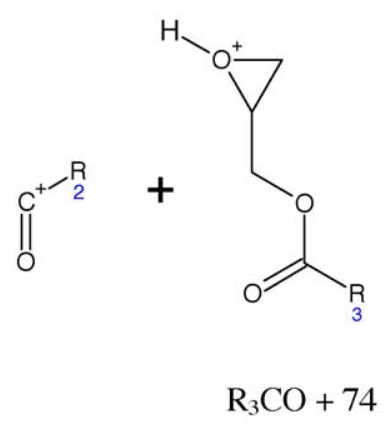

The EIC of ion with $\mathrm{m} / z$ 638 of dioleoylglycerol standard showed intense peaks at 50.6 and $53.6 \mathrm{~min}$ (Fig. 3A). The MS recorded for the former showed ions $m / z, 638(100 \%)$ and 603 $(32 \%)$, corresponding to ions $\left[M+\mathrm{NH}_{4}\right]^{+}$and $\left[M+\mathrm{NH}_{4}-\right.$ $\left.\mathrm{NH}_{3}-\mathrm{H}_{2} \mathrm{O}\right]^{+}$, respectively (Table 3, Fig. 3C). In the CID of $\left[M+\mathrm{NH}_{4}\right]^{+}$with $\mathrm{m} / z, 638$, recorded at $50.5 \mathrm{~min}$, an intense ion with $\mathrm{m} / \mathrm{z}, 603$ was formed by cleavage of ammonia and water (Table 3, Fig. 3E). The $\mathrm{MS}^{2}\left[M+\mathrm{NH}_{4}-\mathrm{NH}_{3}-\mathrm{H}_{2} \mathrm{O}\right]^{+}$with $\mathrm{m} / \mathrm{z}$ 603, recorded at $50.7 \mathrm{~min}$ showed [Acyl 18:1] $]^{+}$ion with $\mathrm{m} / z 265$ (100), [Acyl 18:1- $\left.\mathrm{H}_{2} \mathrm{O}\right]^{+}$ion with $\mathrm{m} / z 247$ (85), and $\left[M+\mathrm{NH}_{4}-\mathrm{NH}_{3}-74\right]^{+}$ion with $m / z 529$ (10\%) (Table 3, Fig. 3D).

The high abundance $\left[M+\mathrm{NH}_{4}-\mathrm{NH}_{3}\right]^{+}$ion with $m / z 569$, in the $\mathrm{LC}-\mathrm{MS}^{2}\left[M+\mathrm{NH}_{4}\right]^{+}$of 1,3-dihexadecanoylglycerol, suggests the stepwise mechanism for fragmentation of 1,3-DAGs proposed in Scheme 2a. In the first step (1), the ammonium ion of $\left[M+\mathrm{NH}_{4}\right]^{+} \mathbf{1}$ donates a proton to the hydroxyl at the 2-position and ammonia and protonated molecular ion (oxonium ion) $\mathbf{2}$ are concomitantly formed. In the second step (2), water is cleaved from oxonium ion $\mathbf{2}$, and the carbocation formed primarily is isomerized to DAG ions $\mathbf{3 a}$ and $\mathbf{3 b}$ or to $\mathbf{3}^{\prime}$ and $\mathbf{3} \mathbf{b}^{\prime}$, which are stabilized by five- or six-membered rings, respectively. Finally, in the third step (3), acyl ions $\mathbf{4 a}$ and $\mathbf{4 b}$ are cleaved from $\mathbf{3 a}$ and $\mathbf{3 b}$ or from $\mathbf{3} \mathbf{a}^{\prime}$ and $\mathbf{3} \mathbf{b}^{\prime}$, respectively.

MS of dioleoylglycerol standard, recorded at $53.6 \mathrm{~min}$, showed an intense $\left[M+\mathrm{NH}_{4}\right]^{+}$ion $m / z 638$ (Table 3, Fig. 3F). In the CID of $\left[M+\mathrm{NH}_{4}\right]^{+}$ion with $\mathrm{m} / z$ 638, recorded at $53.9 \mathrm{~min}$, an intense ion with $\mathrm{m} / z, 339$ (100\%) was formed by cleavage of ammonia and oleic acid and medium intensity ions with $\mathrm{m} / \mathrm{z}$ 621 (22\%) and 603 (46\%) were formed by loss of ammonia, and ammonia and water, respectively (Table 3 , Fig. 3G). The medium intensity $\left[M+\mathrm{NH}_{4}-\mathrm{NH}_{3}\right]^{+}$ion with $\mathrm{m} / 2.621(22 \%)$ detected supports the proposed stepwise fragmentation path of 1,2-DAGs (Scheme 2b). In the first step (1), the ammonium ion of $\left[M+\mathrm{NH}_{4}\right]^{+} \mathbf{1}$ of 1,2-DAG donates a proton to the hydroxyl or the carboxyl oxygen, hence leading to formation of oxonium ions $\mathbf{2 a}, \mathbf{2 b}$, and $\mathbf{2 c}$, along with ammonia. In the second step (2), water is cleaved from oxonium ion $\mathbf{2 a}$, and the carboca- 

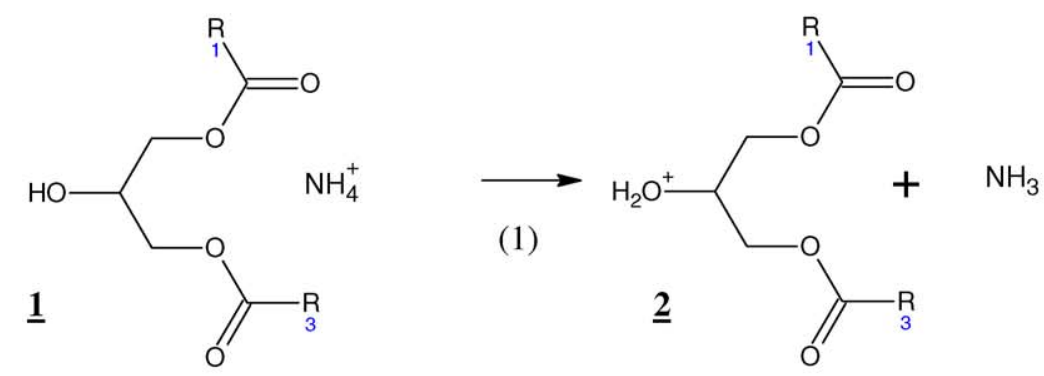

(2)

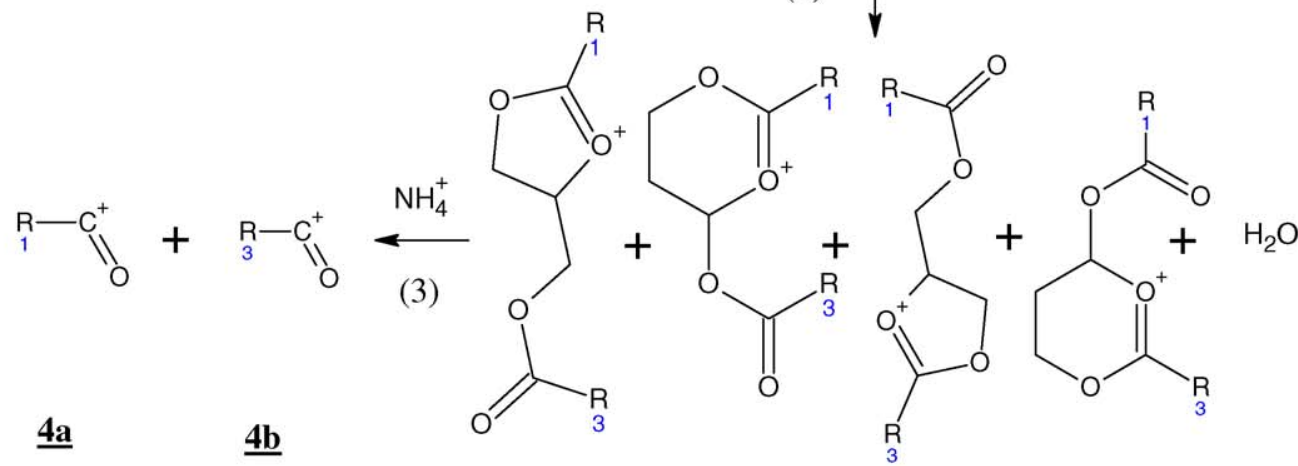

(a)

$\underline{3 a}$

3a'

$\underline{3 b}$

$\underline{3 b^{\prime}}$<smiles>[R]C(=O)OCC(CO)OC([2H])=O</smiles>

(1)<smiles></smiles><smiles>[2H]C(=O)OCC(CO)OC(=O)P</smiles>

$\underline{2 b}$<smiles>[3H][TeH]</smiles><smiles>[2H]C(=O)OC(CO)C[GeH]C(=O)[18OH]</smiles>

$\underline{2 c}$<smiles>[2H]C(=O)[OH+][CH-]CC1COC(P)=[O+]1</smiles>

(b)<smiles>[2H]C(=[OH+])[PH2+]C1=[O+]CC(CO)O1</smiles>

$\underline{4 b}$

Scheme 2.

tion formed primarily is isomerized to DAG ions $\mathbf{3 a}$ and $\mathbf{3 b}$, which are stabilized by five- and six-membered rings, respectively, whereas the FA is released from oxonium ions $\mathbf{2 b}$ and $\mathbf{2 c}$ and MAG ions $\mathbf{4 a}$ and $\mathbf{4 b}$ are formed, which are stabilized by five-membered rings.
The data presented above show that 1,3- and 1,2-DAGs have different fragmentation paths. Characteristic for $\mathrm{MS}^{2}$ $\left[M+\mathrm{NH}_{4}\right]^{+}$of $1,3-\mathrm{DAGs}$ are abundant $\left[M+\mathrm{NH}_{4}-\right.$ $\left.\mathrm{NH}_{3}-\mathrm{H}_{2} \mathrm{O}\right]^{+}\left([\mathrm{DAG}]^{+}\right)$or $\left[M+\mathrm{NH}_{4}-\mathrm{NH}_{3}\right]^{+}$ions. The CID of $\left[M+\mathrm{NH}_{4}-\mathrm{NH}_{3}-\mathrm{H}_{2} \mathrm{O}\right]^{+}$yields characteristic [Acyl] ${ }^{+}$and 


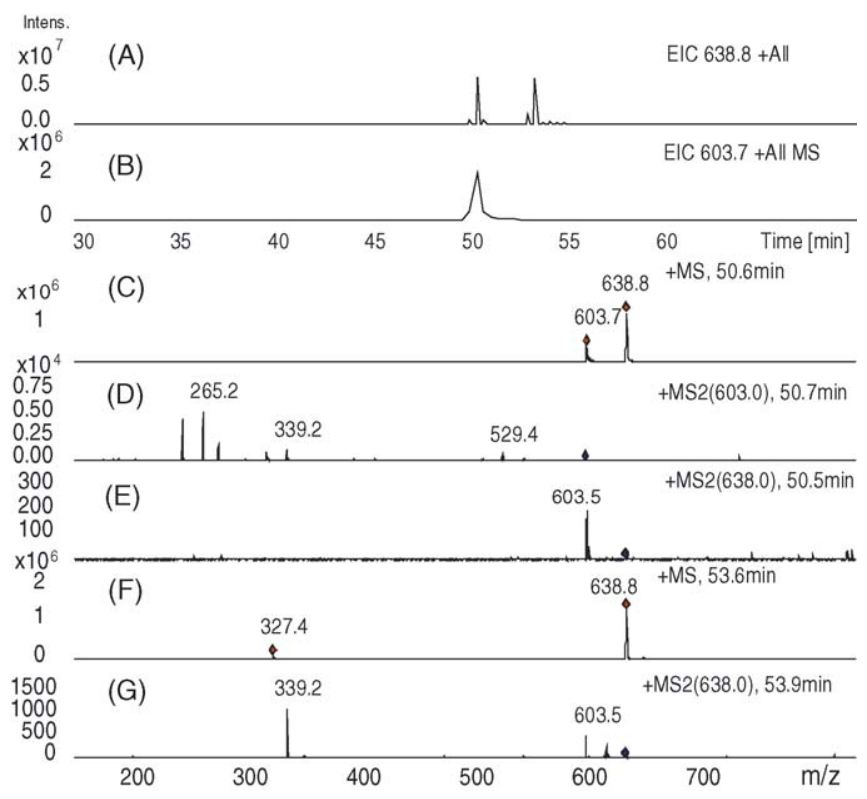

Fig. 3. Mass spectrometric data of regioisomers of dioleoylglycerol recorded in the liquid chromatography-mass spectrometry mode. (A) Extracted ion chromatogram of ammonium adduct. (B) Extracted ion chromatogram of diacylglycerol ion with $\mathrm{m} / z$ 603. (C) Mass spectrum at $50.6 \mathrm{~min}$. (D) Tandem mass spectrum of ion with $\mathrm{m} / z 603$ at $50.7 \mathrm{~min}$. (E) Tandem mass spectrum of ammonium adduct $(\mathrm{m} / \mathrm{z} 638)$ at $50.5 \mathrm{~min}$. (F) Mass spectrum at $53.6 \mathrm{~min}$. (G) Tandem mass spectrum of ammonium adduct $(\mathrm{m} / \mathrm{z} 638)$ at $53.9 \mathrm{~min}$.

[Acyl $\left.-\mathrm{H}_{2} \mathrm{O}\right]^{+}$ions. On the other hand, characteristic for $\mathrm{MS}^{2}$ of $\left[M+\mathrm{NH}_{4}\right]^{+}$ion of 1,2-DAGs are abundant MAG ion $\left[\left(M+\mathrm{NH}_{4}\right)-\mathrm{NH}_{3}-\mathrm{FA}\right]^{+}$and medium intensity $\left[M+\mathrm{NH}_{4}-\right.$ $\left.\mathrm{NH}_{3}\right]^{+}$and $\left[\left(M+\mathrm{NH}_{4}\right)-\mathrm{NH}_{3}-\mathrm{H}_{2} \mathrm{O}\right]^{+}\left([D A G]^{+}\right)$ions. These different fragmentation paths thus enable mass spectrometric identification of regioisomers of DAGs.

\section{Monoacylglycerols (MAGs)}

In FI-MS of linolenoyl-, linoleoyl-, 1-oleoyl-, and 1-palmitoylglycerol, and in LC-MS of stearoylglycerol, $\left[M+\mathrm{NH}_{4}\right]^{+}$ ion was the base peak or a very abundant peak, whereas $\left[\left(M+\mathrm{NH}_{4}\right)-\mathrm{NH}_{3}\right]^{+}$ion was a medium-to-high abundance peak (Table 4). Furthermore, in MS of 1-palmitoyl- and stearoylglycerol a low abundance $\left[\left(M+\mathrm{NH}_{4}\right)-\mathrm{NH}_{3}-\mathrm{H}_{2} \mathrm{O}\right]^{+}$ ion was observed. The $\mathrm{MS}^{2}\left[M+\mathrm{NH}_{4}\right]^{+}$of the respective MAGs showed very abundant (100\% or close to100\%) peaks of $\left[\left(M+\mathrm{NH}_{4}\right)-\mathrm{NH}_{3}\right]^{+}$ions and low-to-high abundance peaks of MAG ions $\left[\left(M+\mathrm{NH}_{4}\right)-\mathrm{NH}_{3}-\mathrm{H}_{2} \mathrm{O}\right]^{+}$(Table 4, Fig. 4A). In FI-MS ${ }^{3}\left[M+\mathrm{NH}_{4}\right]^{+} \rightarrow\left[\left(M+\mathrm{NH}_{4}\right)-\mathrm{NH}_{3}\right]^{+}$of unsaturated MAGs medium-to-high abundance (18-100\%) peaks of MAG ions $\left[\left(M+\mathrm{NH}_{4}\right)-\mathrm{NH}_{3}-\mathrm{H}_{2} \mathrm{O}\right]^{+}$were observed, as well as very abundant $(100 \%)[\mathrm{Acyl}]^{+}$ions and medium abundance $\left[\mathrm{Acyl}-\mathrm{H}_{2} \mathrm{O}\right]^{+}$ions (Table 4, Fig. 4B). The FI-MS $3\left[M+\mathrm{NH}_{4}\right]^{+} \rightarrow\left[\left(M+\mathrm{NH}_{4}\right)-\mathrm{NH}_{3}-\mathrm{H}_{2} \mathrm{O}\right]^{+}$of unsaturated MAGs showed very abundant peaks of $[\mathrm{Acyl}]^{+}$and abundant peaks of $\left[\text { Acyl }-\mathrm{H}_{2} \mathrm{O}\right]^{+}$ions (Table 4, Fig. 4C). In the FI-MS ${ }^{3}\left[M+\mathrm{NH}_{4}\right]^{+} \rightarrow\left[\left(M+\mathrm{NH}_{4}\right)-\mathrm{NH}_{3}\right]^{+}$of 1 hexadecanoylglycerol, a very abundant peak of $\left[\left(M+\mathrm{NH}_{4}\right)-\right.$ $\left.\mathrm{NH}_{3}-\mathrm{H}_{2} \mathrm{O}\right]^{+}$ion and a low abundance peak of [Acyl] $]^{+}$ 
Table 4

Characteristic ions in full scan and product ion tandem mass spectra of monoacylglycerols recorded in flow injection (FI) and liquid chromatography mass spectrometry (LC-MS) modes

\begin{tabular}{|c|c|c|c|c|c|c|c|}
\hline Standard & MS type & {$\left[M+\mathrm{NH}_{4}\right]^{+}, \mathbf{1}^{\mathrm{a}}$} & {$\left[M+\mathrm{NH}_{4}-\mathrm{NH}_{3}\right]^{+}, 2^{\mathrm{a}}$} & {$\left[M+\mathrm{NH}_{4}-\mathrm{NH}_{3}-\mathrm{H}_{2} \mathrm{O}\right]^{+}, 3^{\mathrm{a}}$} & {$[\text { Acid }+\mathrm{H}]^{+}, \mathbf{4}^{\mathrm{a}}$} & {$[\mathrm{Acyl}]^{+}, \mathbf{5}^{\mathrm{a}}$} & {$\left[\mathrm{Acyl}-\mathrm{H}_{2} \mathrm{O}\right]^{+}$} \\
\hline \multirow[t]{3}{*}{ MAG 18:3 FI } & MS & $370(100)^{b}$ & $353(25)$ & & & $261(8)$ & \\
\hline & MS2 370 & & $353(100)$ & $335(14)$ & $279(3)$ & $261(23)$ & $243(14)$ \\
\hline & MS3 $370 \rightarrow 353$ & & & $335(18)$ & $279(13)$ & $261(100)$ & $243(46)$ \\
\hline \multirow[t]{4}{*}{ MAG 18:2 FI } & MS & $372(100)$ & $355(14)$ & & & & \\
\hline & MS2 372 & & $355(100)$ & $337(96)$ & & $263(53)$ & $245(28)$ \\
\hline & MS3 $372 \rightarrow 355$ & & & $337(78)$ & & $263(100)$ & $245(54)$ \\
\hline & MS3 $372 \rightarrow 337$ & & & & & $263(100)$ & $245(58)$ \\
\hline \multirow[t]{4}{*}{ 1-MAG 18:1 FI } & MS & $374(100)$ & $357(28)$ & & & & \\
\hline & MS2 374 & & $357(82)$ & $339(100)$ & $283(5)$ & $265(7)$ & $247(2)$ \\
\hline & MS3 $374 \rightarrow 357$ & & & $339(62)$ & $283(56)$ & $265(100)$ & $247(30)$ \\
\hline & MS3 $374 \rightarrow 339$ & & & & $283(18)$ & $265(100)$ & $247(44)$ \\
\hline \multirow[t]{4}{*}{ 1-MAG 16:0 FI } & MS & $348(95)$ & $331(100)$ & $313(6)$ & & & \\
\hline & MS2 348 & & $331(100)$ & $313(28)$ & & & \\
\hline & MS3 $348 \rightarrow 331$ & & & $313(100)$ & & $239(6)$ & \\
\hline & MS3 $348 \rightarrow 313$ & & & & $257(100)$ & & \\
\hline \multirow[t]{2}{*}{ MAG 18:0 LC-MS } & MS & $376(100)$ & $359(85)$ & $341(7)$ & & & \\
\hline & MS2 376 & & $359(100)$ & & & & \\
\hline MS2 359 & & & $341(100)$ & & & & \\
\hline \multicolumn{8}{|l|}{ MAG 16:0 } \\
\hline \multirow[t]{2}{*}{ LC-MS } & MS & $348(81)$ & $331(100)$ & $313(5)$ & & $239(2)$ & \\
\hline & MS2 331 & & & $313(100)$ & & & \\
\hline \multicolumn{8}{|l|}{ MAG 12:0 } \\
\hline \multirow{2}{*}{ LC-MS } & MS & $292(38)$ & $275(100)$ & $257(7)$ & & & \\
\hline & MS2 292 & & $275(100)$ & $257(5)$ & & & \\
\hline
\end{tabular}

a Refer to the structure proposed in Scheme 3

${ }^{b} \mathrm{~m} / \mathrm{z}$ (abundance \%). 


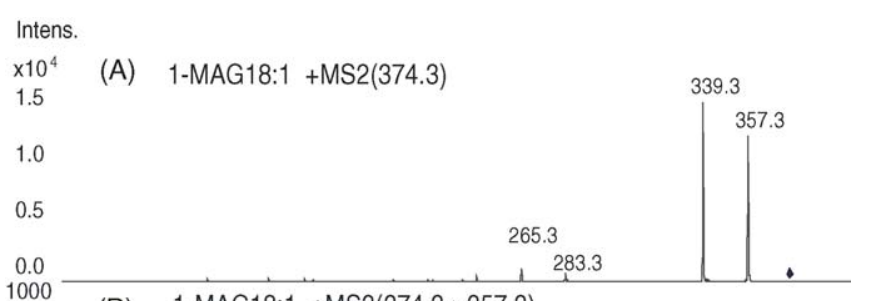

(B) 1-MAG18:1 +MS3(374.3->357.3)

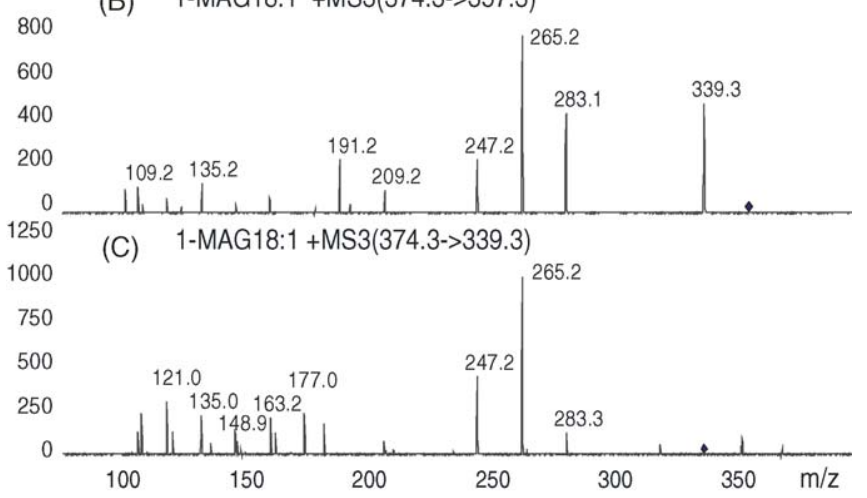

Fig. 4. Mass spectrometric data of 1-oleoyl-rac-glycerol. (A) Tandem mass spectrum of ammonium adduct ( $\mathrm{m} / \mathrm{z} 374$ ). (B) Mass spectrum of ion with $\mathrm{m} / \mathrm{z} 357$ produced in collision induced decay of ammonium adduct $=\mathrm{MS}^{3}(374 \rightarrow 357)$. (C) Mass spectrum of ion $m / z 339$ produced in collision induced decay of ammonium adduct $=\mathrm{MS}^{3}(374 \rightarrow 339)$.

ion were observed (Table 4). The FI-MS ${ }^{3}\left[M+\mathrm{NH}_{4}\right]^{+}$ $\rightarrow\left[\left(M+\mathrm{NH}_{4}\right)-\mathrm{NH}_{3}-\mathrm{H}_{2} \mathrm{O}\right]^{+}$of 1-hexadecanoylglycerol showed the $[\text { Acid }+\mathrm{H}]^{+}$ion solely.

The $\mathrm{MS}^{2}\left[M+\mathrm{NH}_{4}\right]^{+}, \mathrm{MS}^{3}\left[M+\mathrm{NH}_{4}\right]^{+} \rightarrow\left[\left(M+\mathrm{NH}_{4}\right)-\right.$ $\left.\mathrm{NH}_{3}\right]^{+}$, and $\mathrm{MS}^{3}\left[M+\mathrm{NH}_{4}\right]^{+} \rightarrow\left[\left(M+\mathrm{NH}_{4}\right)-\mathrm{NH}_{3}-\mathrm{H}_{2} \mathrm{O}\right]^{+}$ (Table 4) indicate clearly a stepwise fragmentation mechanism depicted in Scheme 3. The $\mathrm{MS}^{2}\left[M+\mathrm{NH}_{4}\right]^{+}$indicate that, in the first step (1) of the proposed fragmentation mechanism,
$\mathrm{NH}_{4}{ }^{+}$ion of $\left[M+\mathrm{NH}_{4}\right]^{+} \mathbf{1}$ donates a proton to one of the hydroxyl groups, ammonia is released, and oxonium ion $\mathbf{2 a}$ or 2b is formed. The FI-MS ${ }^{3}\left[M+\mathrm{NH}_{4}\right]^{+} \rightarrow\left[\left(M+\mathrm{NH}_{4}\right)-\mathrm{NH}_{3}\right]^{+}$ reveal that, in the second step (2), water is cleaved from oxonium ion $\mathbf{2 a}$ or $\mathbf{2 b}$ and MAG ion $\mathbf{3 a}$ or $\mathbf{3 b}$ is formed, which is stabilized by five- or six-membered ring. The FI-MS ${ }^{3}$ $\left[M+\mathrm{NH}_{4}\right]^{+} \rightarrow\left[\left(M+\mathrm{NH}_{4}\right)-\mathrm{NH}_{3}-\mathrm{H}_{2} \mathrm{O}\right]^{+}$suggest that, in the third step (3), ion $\mathbf{3 a}$ or $\mathbf{3 b}$ is decomposed, and a protonated fatty acid ion $\mathbf{4}$ is formed. The ion $\mathbf{4}$ decomposes to [Acyl] ${ }^{+}$ion $\mathbf{5}$ and water, in the fourth step (4).

\section{Sterol esters (SEs)}

In the FI-MS of cholesteryl linoleate, $\left[M+\mathrm{NH}_{4}\right]^{+}$was the base peak, and characteristic cholesterol fragment ion with $\mathrm{m} / \mathrm{z}$ 369 was a medium abundance peak $(22 \%)$. In the FI-MS ${ }^{2}$ $\left[M+\mathrm{NH}_{4}\right]^{+}$of cholesterol linolenate, linoleate, and oleate, the cholesterol fragment ion was the base peak and the abundances of $\left[\left(M+\mathrm{NH}_{4}\right)-\mathrm{NH}_{3}\right]^{+}$ion peaks were 4,28 , and $17 \%$, respectively. The FI-MS ${ }^{3}\left[M+\mathrm{NH}_{4}\right]^{+} \rightarrow$ cholesterol fragment ion with $\mathrm{m} / \mathrm{z} 369$, showed further fragments of the fragment ion with $m / z 369$ (Table 5). Accordingly, the LC-MS ${ }^{2}$ $\left[M+\mathrm{NH}_{4}\right]^{+}$of cholesterol linolenate and linoleate showed $100 \%$ peaks of cholesterol fragment ion with $\mathrm{m} / \mathrm{z} 369$, and 7 and $14 \%$ peaks of $\left[\left(M+\mathrm{NH}_{4}\right)-\mathrm{NH}_{3}\right]^{+}$ion, respectively (Table 5). The low-to-medium abundance peaks of $\left[\left(M+\mathrm{NH}_{4}\right)-\mathrm{NH}_{3}\right]^{+}$ ion suggest a stepwise fragmentation mechanism. Similarly, the $\mathrm{MS}^{2}\left[M+\mathrm{NH}_{4}\right]^{+}$of low erucic acid rapeseed oil sterol esters showed abundant peaks (100\%) of characteristic S fragment ions, $m / z 381,383$, and 397, and low abundance (2-9\%) $\left[\left(M+\mathrm{NH}_{4}\right)-\mathrm{NH}_{3}\right]^{+}$ions (Table 8$)$. The $\mathrm{MS}^{2}$ spectra of these characteristic fragment ions were similar to the $\mathrm{MS}^{2}$ spectra of free sterol fragment ions.

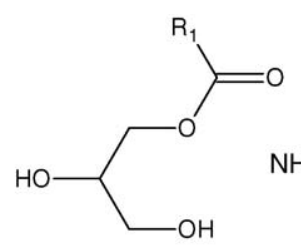

$\underline{1}$<smiles>[B]C(=O)OCC(CO)[OH+][CH-]C(=O)[PH]</smiles>

$\underline{2 \mathrm{a}}$

$\underline{2 b}$
(2)

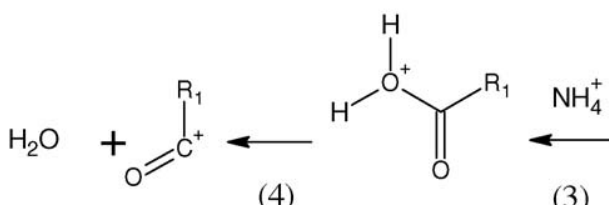

(4)

(3) $\underline{\mathbf{5}}$<smiles>[B]C1=[O+]C(CO)CO1</smiles> 
Table 5

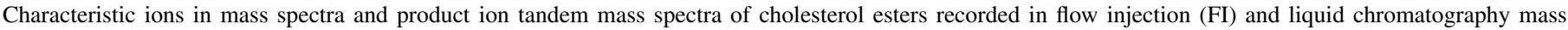
spectrometry (LC-MS) mode

\begin{tabular}{|c|c|c|c|c|c|}
\hline Standard & MS type & {$\left[M+\mathrm{NH}_{4}\right]^{+}$} & {$\left[M+\mathrm{NH}_{4}-\mathrm{NH}_{3}\right]^{+}$} & $\begin{array}{l}{\left[M+\mathrm{NH}_{4}-\mathrm{NH}_{3}-\mathrm{FA}\right]^{+}} \\
\text {cholesterol fragment ion }\end{array}$ & Other \\
\hline CE 18:3 FI & $\begin{array}{l}\text { MS2 } 664 \\
\text { MS3 } 664 \rightarrow 369\end{array}$ & & $647(4)^{\mathrm{a}}$ & $369(100)$ & $\begin{array}{l}607(9), 551(32) \\
135,147,149,159,161,189,217,229,233, \\
243,257,259,273,287,313\end{array}$ \\
\hline CE 18:2 FI & $\begin{array}{l}\text { MS } \\
\text { MS2 } 666 \\
\text { MS3 } 666 \rightarrow 369\end{array}$ & $666(100)$ & $649(28)$ & $\begin{array}{l}369(22) \\
369(100)\end{array}$ & $\begin{array}{l}135,147,149,161,175,189,203,215,233 \\
243,257,259\end{array}$ \\
\hline CE 18:1 FI & MS2 668 & & $651(17)$ & $369(100)$ & \\
\hline $\begin{array}{l}\text { CE 18:3 LC-MS } \\
\text { CE 18:2 LC-MS }\end{array}$ & $\begin{array}{l}\text { MS2 } 664 \\
\text { MS2 } 666\end{array}$ & & $\begin{array}{l}647(7) \\
649(14)\end{array}$ & $\begin{array}{l}369(100) \\
369(100)\end{array}$ & $607(74), 551(60)$ \\
\hline
\end{tabular}

a $m / z$ (abundance percentage).

Free sterols (Ss)

In the LC-MS, ion chromatograms of characteristic sterol fragment ions 381, 383, 395, and 397 were recorded. The $\mathrm{MS}^{2}$ spectra of these characteristic fragment ions were similar to those of sterol esters. Several fragment ions were common in the $\mathrm{MS}^{2}$ spectra of the characteristic fragment ions of all plant sterol species (Table 8) and cholesterol (Table 5), but a few fragment ions were specific for a certain sterol species. In addition to these, several fragment ions were characteristic to the $\mathrm{S}$ with saturated side chain (campesterol and sitosterol).

\section{Free fatty acids (FFAs)}

FI-MS of $\left[M+\mathrm{NH}_{4}\right]^{+}$of unsaturated FFAs showed abundant $(100 \%)$ peaks of $\left[M+\mathrm{NH}_{4}\right]^{+}$and low intensity $[\text {Acid }+\mathrm{H}]^{+}$ ion peaks (Fig. 5, Table 6). In the FI-MS ${ }^{2}\left[M+\mathrm{NH}_{4}\right]^{+}$, abundant $[\text { Acid }+\mathrm{H}]^{+}$ions, low-to-high abundance $[\text {Acyl }]^{+}$ions, and low-to-medium abundance $\left[\mathrm{Acyl}-\mathrm{H}_{2} \mathrm{O}\right]^{+}$ions were observed. The FI-MS ${ }^{3}\left[M+\mathrm{NH}_{4}\right]^{+} \rightarrow[\text { Acid }+\mathrm{H}]^{+}$showed $[\text {Acyl }]^{+}$ions as base peak and medium abundance peaks of $\left[\text { Acyl }-\mathrm{H}_{2} \mathrm{O}\right]^{+}$ ions. The $\mathrm{MS}^{2}\left[M+\mathrm{NH}_{4}\right]^{+}$of saturated FFAs showed abundant $(100 \%)[\text { Acid }+\mathrm{H}]^{+}$ions, whereas the $\mathrm{MS}^{2}\left[M+\mathrm{NH}_{4}-\mathrm{H}\right]^{+}$ showed [Acid] ${ }^{+}$ions solely (Table 7 ). The MS data of unsaturated FFAs is consistent with the mechanism presented in the Scheme 4: In the first step (1), ammonium ion in $\left[M+\mathrm{NH}_{4}\right]^{+}$ 1 donates proton to carboxyl oxygen of FA, in the second step (2), water is cleaved from [Acid $+\mathrm{H}]^{+}$ion $\mathbf{2}$ and [Acyl] $]^{+}$ion $\mathbf{3}$ is formed. In the third step (3), water is cleaved from $[\text { Acyl }]^{+}$ion.

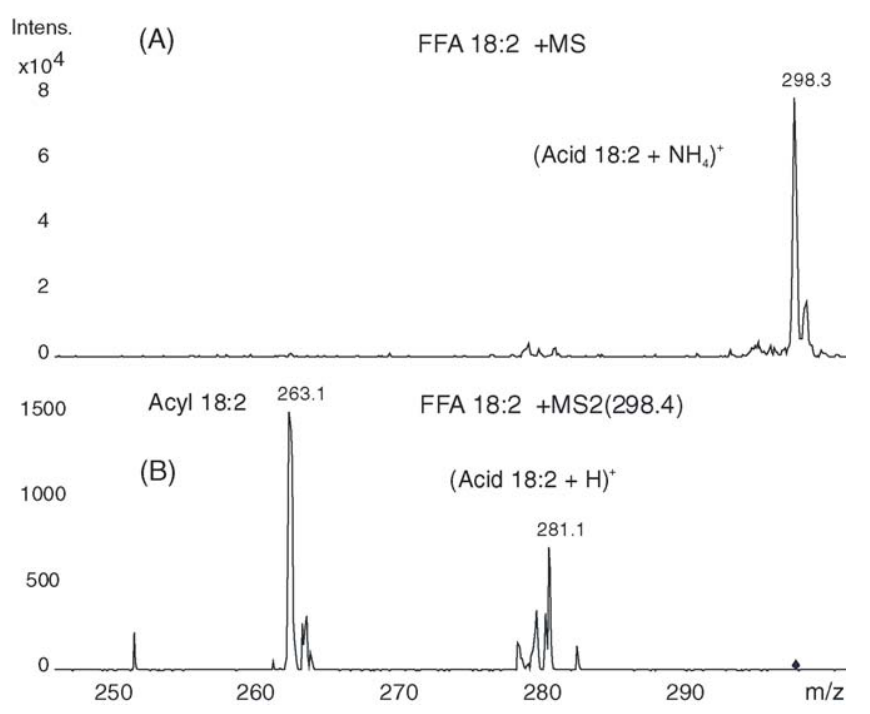

Fig. 5. Mass spectrometric data of linoleic acid recorded in the liquid chromatography-mass spectrometry mode. (A) Mass spectrum of ammonium adduct with $\mathrm{m} / \mathrm{z}$ 298. (B) Tandem mass spectrum of ammonium adduct with $\mathrm{m} / \mathrm{z}$ 298.

\section{Analysis of low erucic acid rapeseed oil lipids}

The full scan ESI-MS were recorded in one set of experiments using the method developed for SEs, TAGs, and DAGs, and in another set with that developed for Ss, MAGs, and FFAs. The MS for peaks in the reconstructed ion chromatogram were extracted from computer, so as to reveal the $m / z$ values of $\left[M+\mathrm{NH}_{4}\right]^{+}$ion

Table 6

Characteristic ions in full scan and product ion tandem mass spectra of unsaturated free fatty acid recorded in flow injection mode

\begin{tabular}{|c|c|c|c|c|c|}
\hline Standard & MS type & {$\left[M+\mathrm{NH}_{4}\right]^{+}, \mathbf{1}^{\mathrm{a}}$} & {$[\text { Acid }+\mathrm{H}]^{+}, 2^{\mathrm{a}}$} & {$[\text { Acyl }]^{+}, \mathbf{3}^{\mathrm{a}}$} & {$\left[\mathrm{Acyl}-\mathrm{H}_{2} \mathrm{O}\right]^{+}$} \\
\hline \multirow[t]{3}{*}{ FFA $18: 3$} & MS & $296(100)^{b}$ & $279(7)$ & & \\
\hline & MS2 296 & & $279(100)$ & $261(8)$ & $243(8)$ \\
\hline & MS3 $296 \rightarrow 279$ & & & $261(100)$ & $243(37)$ \\
\hline \multirow[t]{4}{*}{ FFA $18: 2$} & MS & $298(100)$ & & & \\
\hline & MS2 298 & & $281(60)$ & $263(100)$ & $245(23)$ \\
\hline & MS3 $298 \rightarrow 281$ & & & $263(100)$ & $245(60)$ \\
\hline & MS3 $298 \rightarrow 263$ & & & & $245(100)$ \\
\hline
\end{tabular}

\footnotetext{
a Refer to the proposed structure in Scheme 4

b $m / z$ (abundance $\%$ ).
} 
Table 7

Characteristic ions in product ion tandem mass spectra of saturated free fatty acids recorded in flow injection mode

\begin{tabular}{llll}
\hline Standard & MS type & {$[\text { Acid }+\mathrm{H}]^{+}$} & {$[$Acid] } \\
\hline FFA 18:0 & MS2 $301^{\mathrm{a}}$ & & $284(100)$ \\
FFA 18:0 & MS2 302 & \\
FFA 16:0 & MS2 273 & $285(100)^{\mathrm{c}}$ & $256(100)$ \\
FFA 16:0 & MS2 274 & & \\
\hline
\end{tabular}

a $\mathrm{MS} 2\left[M+\mathrm{NH}_{4}-1\right]^{+}$.

b $\mathrm{MS} 2\left[M+\mathrm{NH}_{4}\right]^{+}$.

c $m / z$ (abundance \%).

(or other precursor ion) of major and minor components of each lipid class. The EICs of $\left[M+\mathrm{NH}_{4}\right]^{+}$of SEs, TAGs, MAGs, and FFAs, those of $\left[M+\mathrm{NH}_{4}\right]^{+}$and $\left[\left(M+\mathrm{NH}_{4}\right)-\mathrm{NH}_{3}-\mathrm{H}_{2} \mathrm{O}\right]^{+}$of DAGs, and those of characteristic fragment ions of free sterols were integrated. For calculation of lipid class composition the integrated areas were corrected by amount/area ratios determined for standards. Auto-MS/MS spectra were recorded using the two methods and interpreted (Table 8).

Major and a part of minor molecular species of the 17 ACN:DB classes of TAGs could be identified from DAG ions $\left[\left(M+\mathrm{NH}_{4}\right)-\mathrm{NH}_{3}-\mathrm{FA}\right]^{+}$. In the recent studies $[7,8]$ of shortchain TAGs, using essentially the same method than in the present study, 4-11 times lower abundance of the ion formed by cleavage of FA from the $s n-2$ position relative to that formed by cleavage from $s n-1$ or -3 positions was observed. Here, we recorded $\mathrm{MS}^{2}$ for $\left[M+\mathrm{NH}_{4}\right]^{+}$of 1-lauroyl-2-oleoyl3-palmitoyl-rac-glycerol in LC-MS mode. The relative abundances of $\left[\left(M+\mathrm{NH}_{4}\right)-\mathrm{NH}_{3}-\mathrm{FA}\right]^{+}$were 39.8/17.3/42.9 for the ions formed by cleavage of FA from 1-, 2-, and 3-position, respectively. The abundances, similar to those observed for longchain acyl/short-chain acyl/long-chain acyl isomers of three acid TAGs [7] are applicable in identification of regioisomers. For most molecular species the principal regioisomer could be identified (Table 8).

1,3-DAGs were identified from $\mathrm{MS}^{2}$ of DAG ions $\left[\left(M+\mathrm{NH}_{4}\right)\right.$ $\left.-\mathrm{NH}_{3}-\mathrm{H}_{2} \mathrm{O}\right]^{+}$, which showed characteristic [Acyl] ${ }^{+}$ions, and the 1,2-DAGs from $\mathrm{MS}^{2}\left[M+\mathrm{NH}_{4}\right]^{+}$ions, which showed characteristic MAG ions $\left[\left(M+\mathrm{NH}_{4}\right)-\mathrm{NH}_{3}-\mathrm{FA}\right]^{+}$. The sum of 1,3and 1,2-DAGs was calculated from the corrected areas, and the

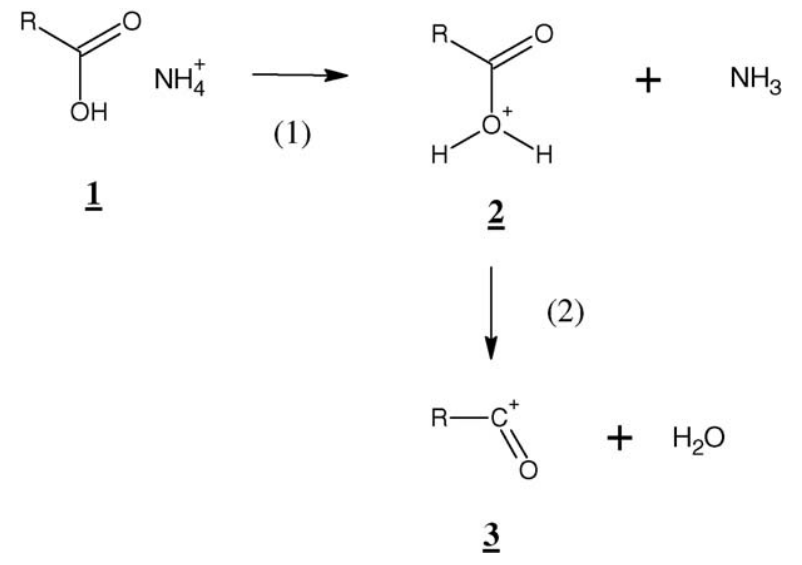

Scheme 4. area ratios of regioisomers were calculate, as well. MAGs were identified from $\mathrm{MS}^{2}\left[M+\mathrm{NH}_{4}\right]^{+}$, which showed characteristic $[\text { Acyl }]^{+}$and $\left[\text {Acyl }-\mathrm{H}_{2} \mathrm{O}\right]^{+}$ions.

Sterol species and esterified FAs could be identified from $\mathrm{MS}^{2}\left[M+\mathrm{NH}_{4}\right]^{+}$of SEs, which showed $\left[\left(M+\mathrm{NH}_{4}\right)-\mathrm{NH}_{3}\right]^{+}$ and characteristic sterol fragment ion. The esterified FA was apparent via the $m / z$ difference $\left[M+\mathrm{NH}_{4}\right]^{+}-\mathrm{NH}_{3}-$ [sterol fragment ion $]^{+}$. In three $\left[M+\mathrm{NH}_{4}\right]^{+}$ions, two isobaric SEs were identified. The composition (\%) of each $\left[M+\mathrm{NH}_{4}\right]^{+}$ion was calculated from corrected areas. In order to obtain the percentage of isobaric SEs, the percentage of $\left[M+\mathrm{NH}_{4}\right]^{+}$ions with two isobaric SE was divided in the ratio of abundances of characteristic sterol fragment ions in the respective $\mathrm{MS}^{2}$ of $\left[M+\mathrm{NH}_{4}\right]^{+}$. Free sterols could be identified from characteristic fragment ions. The identity of unsaturated FFAs was confirmed by $\mathrm{MS}^{2}$ $\left[M+\mathrm{NH}_{4}\right]^{+}$, which showed [Acyl] ${ }^{+}$ions and that of saturated FFAs by $\mathrm{MS}^{2}\left[M+\mathrm{NH}_{4}-\mathrm{H}\right]^{+}$, which showed $[\text {Acid }+\mathrm{H}]^{+}$or $[\text { Acid }]^{+}$ions.

\section{Discussion}

\section{Triacylglycerols (TAGs)}

Lauer et al. [32] have studied EI-MS of TAGs and observed prominent $\left[M-\mathrm{RCO}_{2}\right]^{+},\left[M-\mathrm{RCOOCH}_{2}\right]^{+},[\mathrm{Acyl}+74]^{+}$ions among others, and postulated the presence of stable five- and sixmembered rings in the $\left[M-\mathrm{RCO}_{2}\right]^{+}$ions and the formation of $[\text { Acyl }+74]^{+}$ion by ketene loss from $\left[M-\mathrm{RCOO}^{+}\right.$ion. Duffin et al. [2] proposed, that carbocations $\left[\left(M+\mathrm{NH}_{4}\right)-\mathrm{NH}_{3}-\mathrm{FA}\right]^{+}$ and $[\text { Acyl }+74]^{+}$, and $[\text {Acyl }]^{+}$ions are produced from the dissociation of $\left[M+\mathrm{NH}_{4}\right]^{+}$. Cheng et al. [3] suggested concerted mechanism for fragmentation of ESI-produced ammonium adduct ions of TAG, according to which the $\left[\left(M+\mathrm{NH}_{4}\right)-\mathrm{NH}_{3}-\mathrm{FA}\right]^{+}$and $[\text {Acyl }]^{+}$ions are formed directly from $\left[M+\mathrm{NH}_{4}\right]^{+}$, and the $[\mathrm{Acyl}+74]^{+}$ions are formed by ketene loss from DAG ion $\left[\left(M+\mathrm{NH}_{4}\right)-\mathrm{NH}_{3}-\mathrm{FA}\right]^{+}$. Marzilli et al. [6] have studied mixed acid TAG by ESI-MS and found in the $\mathrm{MS}^{3}\left[M+\mathrm{NH}_{4}\right]^{+} \rightarrow\left[\left(M+\mathrm{NH}_{4}\right)-\mathrm{NH}_{3}-\mathrm{FA}\right]^{+}$, saturated and unsaturated $[\text { Acyl }]^{+}$and $[\text {Acyl }+74]^{+}$ions, and ions formed by cleavage of fragment 74 from unsaturated $\left[\left(M+\mathrm{NH}_{4}\right)-\mathrm{NH}_{3}-\mathrm{FA}\right]^{+}$ions. Furthermore, they showed that identical $\mathrm{MS}^{3}\left[M+\mathrm{NH}_{4}\right]^{+} \rightarrow[\mathrm{AB}]^{+}$were obtained from AAB and ABA positional isomers of long-chain TAG. During the time, this paper was written, McAnoy et al. [9] reported $\mathrm{MS}^{2}$ and $\mathrm{MS}^{3}$ data of deuterium labeled saturated, monoene, and triene TAGs, which were measured with a linear ion trap instrument. Their data showed that CID of $\left[M+\mathrm{NH}_{4}\right]^{+}$resulted in the neutral loss of $\mathrm{NH}_{3}$ and acyl chain as carboxylic acid, and the authors suggested a concerted mechanism for formation of diacyl product ion $\left[\left(M+\mathrm{NH}_{4}\right)-\mathrm{NH}_{3}-\mathrm{FA}\right]^{+}$.

In the present study, the dependence of the abundance of the $\left[\left(M+\mathrm{NH}_{4}\right)-\mathrm{NH}_{3}\right]^{+}$(onium ions $\mathbf{2 a}$ and $\mathbf{2 b}$, Scheme 1) on the level of unsaturation suggest that these ions are stabilized by carbon-carbon double bonds. The abundance of ions $\left[\left(M+\mathrm{NH}_{4}\right)-\mathrm{NH}_{3}\right]^{+}$in the $\mathrm{MS}^{2}$ of unsaturated TAGs allowed us to record the FI-MS ${ }^{3}\left[M+\mathrm{NH}_{4}\right]^{+} \rightarrow\left[\left(M+\mathrm{NH}_{4}\right)-\mathrm{NH}_{3}\right]^{+}$ (Table 2), which strongly support the stepwise mechanism. 
Table 8

Characteristic ions in mass spectra and product ion tandem mass spectra, recorded in liquid chromatography mass spectrometry mode, used for identification of molecular species of lipids in rapeseed oil

\begin{tabular}{|c|c|c|c|c|}
\hline $\begin{array}{l}{\left[M+\mathrm{NH}_{4}\right]^{+} \text {or other }} \\
\text { precursor ion }(m / z)\end{array}$ & $\mathrm{RT}^{\mathrm{a}}$ & $\begin{array}{l}\text { Major and (minor) molecular } \\
\text { species; ACN:DB }\end{array}$ & $\begin{array}{l}\text { Characteristic ions in tandem mass } \\
\text { spectra }(m / z)\end{array}$ & $\begin{array}{l}\text { Composition }(\%) \\
\text { (mean and deviation) }\end{array}$ \\
\hline \multicolumn{5}{|l|}{ Sterol esters } \\
\hline \multirow[t]{2}{*}{678.7} & 21.4 & Bra- $18: 2^{\mathrm{c}}$ & $\mathrm{MS}^{2} 678: 661^{\mathrm{d}}, 381^{\mathrm{e}} ; \mathrm{MS}^{2} 381^{\mathrm{f}}$ & $4.9 \pm 0.03^{\mathrm{g}}$ \\
\hline & & Cam-18:3 & $\mathrm{MS}^{2} 678: 661^{\mathrm{d}}, 383^{\mathrm{e}} ; \mathrm{MS}^{2} 383^{\mathrm{f}}$ & $14.5 \pm 0.10$ \\
\hline 680.8 & 21.4 & Cam-18:2 & $\mathrm{MS}^{2}$ 680: $663^{\mathrm{d}}, 383^{\mathrm{e}} ; \mathrm{MS}^{2} 383^{\mathrm{f}}$ & $24.8 \pm 0.11$ \\
\hline \multirow[t]{2}{*}{682.6} & 21.2 & Cam-18:1 & $\mathrm{MS}^{2} 682: 665^{\mathrm{d}} ; 383^{\mathrm{e}} ; \mathrm{MS}^{2} 383^{\mathrm{f}}$ & $7.0 \pm 0.76$ \\
\hline & & Bra-18:0 & $\mathrm{MS}^{2} 682: 665^{\mathrm{d}} ; 381^{\mathrm{e}}$ & $0.8 \pm 0.09$ \\
\hline \multirow[t]{2}{*}{692.8} & 21.4 & Sit-18:3 & $\mathrm{MS}^{2} 692: 675^{\mathrm{d}}, 397^{\mathrm{e}} ; \mathrm{MS}^{2} 397^{\mathrm{f}}$ & $17.5 \pm 0.26$ \\
\hline & & Stig-18:2 & $\mathrm{MS}^{2} 692: 675^{\mathrm{d}}, 395^{\mathrm{e}}$ & $1.6 \pm 0.02$ \\
\hline 694.7 & 21.4 & Sit-18:2 & $\mathrm{MS}^{2}$ 694: $677^{\mathrm{d}}, 397^{\mathrm{e}} ; \mathrm{MS}^{2} 397^{\mathrm{f}}$ & $23.0 \pm 0.57$ \\
\hline 696.6 & 21.5 & Sit-18:1 & $\mathrm{MS}^{2}$ 696: $397^{\mathrm{e}} ; \mathrm{MS}^{2} 397^{\mathrm{f}}$ & $6.0 \pm 0.02$ \\
\hline \multicolumn{5}{|l|}{ Triacylglycerols } \\
\hline 865.3 & 28.3 & $52: 8 ; 16: 3 / 18: 2 / 18: 3^{\mathrm{h}}$ & $\mathrm{MS}^{2} 865: 848^{\mathrm{d}}, 567^{\mathrm{e}}, 569^{\mathrm{e}}, 597^{\mathrm{e}}$ & $0.1 \pm 0.01$ \\
\hline 867.3 & 27.5 & $52: 7 ; 16: 3 / 18: 2 / 18: 2$ & $\mathrm{MS}^{2} 867: 850^{\mathrm{d}}, 570^{\mathrm{e}}, 599^{\mathrm{e}}$ & $0.4 \pm 0.00$ \\
\hline 869.3 & 26.0 & $52: 6,16: 0 / 18: 3 / 18: 3$ & $\mathrm{MS}^{2} 869: 852^{\mathrm{d}}, 573^{\mathrm{e}}, 595^{\mathrm{e}}$ & $1.1 \pm 0.02$ \\
\hline 871.3 & 24.4 & $52: 5 ; 16: 0 / 18: 3 / 18: 2$ & $\mathrm{MS}^{2} 871: 854^{\mathrm{d}}, 573^{\mathrm{e}}, 575^{\mathrm{e}}, 597^{\mathrm{e}}$ & $2.3 \pm 0.02$ \\
\hline 873.3 & 23.3 & $\begin{array}{l}52: 4 ; 16: 0 / 18: 2 / 18: 2 \\
(16: 0 / 18: 1 / 18: 3)\end{array}$ & $\begin{array}{l}\mathrm{MS}^{2} 873: 856^{\mathrm{d}}, 573^{\mathrm{e}}, 575^{\mathrm{e}}, 577^{\mathrm{e}}, \\
599^{\mathrm{e}}\end{array}$ & $3.6 \pm 0.02$ \\
\hline 875.3 & 23.8 & $52: 3 ; 16: 018: 118: 2$ & $\mathrm{MS}^{2} 875: 858^{\mathrm{d}}, 575^{\mathrm{e}}, 577^{\mathrm{e}}, 601^{\mathrm{e}}$ & $3.4 \pm 0.10$ \\
\hline 877.3 & 22.0 & $52: 2 ; 16: 0 / 18: 1 / 18: 1$ & $\mathrm{MS}^{2} 877: 860^{\mathrm{d}}, 577^{\mathrm{e}}, 603^{\mathrm{e}}$ & $2.7 \pm 0.03$ \\
\hline 879.3 & 22.0 & $52: 1 ; 18: 0 / 16: 0 / 18: 1$ & $\mathrm{MS}^{2} 879: 862^{\mathrm{d}}, 577^{\mathrm{e}}, 579^{\mathrm{e}}, 605^{\mathrm{e}}$ & $0.6 \pm 0.03$ \\
\hline 891.3 & 28.1 & $\begin{array}{l}54: 9 ; 18: 3 / 18: 3 / 18: 3 \\
18: 418: 218: 3\end{array}$ & $\mathrm{MS}^{2} 891: 874^{\mathrm{d}}, 593^{\mathrm{e}}, 595^{\mathrm{e}}, 597^{\mathrm{e}}$ & $0.0 \pm 0.00$ \\
\hline 893.3 & 27.4 & $54: 8 ; 18: 3 / 18: 2 / 18: 3$ & $\mathrm{MS}^{2} 893: 876^{\mathrm{d}}, 595^{\mathrm{e}}, 597^{\mathrm{e}}$ & $1.7 \pm 0.04$ \\
\hline 895.3 & 26.4 & $\begin{array}{l}54: 7 ; 18: 3 / 18: 1 / 18: 3 \\
(18: 2 / 18: 3 / 18: 2)\end{array}$ & $\mathrm{MS}^{2} 895: 878^{\mathrm{d}}, 595^{\mathrm{e}}, 597^{\mathrm{e}}, 599^{\mathrm{e}}$ & $7.1 \pm 0.35$ \\
\hline 897.3 & 25.6 & $\begin{array}{l}54: 6 ; 18: 1 / 18: 3 / 18: 2 \\
(18: 2 / 18: 2 / 18: 2)\end{array}$ & $\mathrm{MS}^{2} 897: 880^{\mathrm{d}}, 597^{\mathrm{e}}, 599^{\mathrm{e}}, 601^{\mathrm{e}}$ & $13.8 \pm 0.04$ \\
\hline 899.3 & 23.0 & $\begin{array}{l}54: 5 ; 18: 1 / 18: 3 / 18: 1 \\
(18: 1 / 18: 2 / 18: 2)\end{array}$ & $\mathrm{MS}^{2} 899: 882^{\mathrm{d}}, 599^{\mathrm{e}}, 601^{\mathrm{e}}, 603^{\mathrm{e}}$ & $21.5 \pm 0.47$ \\
\hline 901.3 & 22.3 & $54: 4 ; 18: 1 / 18: 2 / 18: 1$ & $\mathrm{MS}^{2} 903: 884^{\mathrm{d}}, 601^{\mathrm{e}}, 603^{\mathrm{e}}$ & $19.0 \pm 0.07$ \\
\hline 903.3 & 21.8 & $\begin{array}{l}54: 3 ; 18: 1 / 18: 1 / 18: 1 \\
(18: 018: 118: 2)\end{array}$ & $\mathrm{MS}^{2} 901: 886^{\mathrm{d}}, 601^{\mathrm{e}}, 603^{\mathrm{e}}, 605^{\mathrm{e}}$ & $17.9 \pm 0.88$ \\
\hline 905.3 & 21.7 & $54: 2 ; 18: 0 / 18: 1 / 18: 1$ & $\mathrm{MS}^{2} 905: 888^{\mathrm{d}}, 603^{\mathrm{e}}, 605^{\mathrm{e}}$ & $4.3 \pm 0.02$ \\
\hline 907.3 & 21.7 & $54: 1 ; 18: 018: 018: 1$ & $\mathrm{MS}^{2}$ 907: $890^{\mathrm{d}}, 605^{\mathrm{e}}, 607^{\mathrm{e}}$ & $0.4 \pm 0.00$ \\
\hline \multicolumn{5}{|l|}{ Diacylglycerols } \\
\hline \multirow[t]{2}{*}{608.2} & 51.8 & $1,3-34: 3 ; 16: 0 / 18: 3$ & $\mathrm{MS}^{2} 573: 261^{\mathrm{k}}, 243^{\mathrm{k}}$ & \\
\hline & 55.3 & $1,2-34: 3 ; 16: 0 / 18: 3$ & $\mathrm{MS}^{2} 608: 591^{\mathrm{d}}, 573^{\mathrm{i}}, 313^{\mathrm{e}}, 335^{\mathrm{e}}$ & $1.4 \pm 0.03^{\mathrm{g}} ; 0.92^{\mathrm{j}}$ \\
\hline \multirow[t]{2}{*}{610.7} & 51.5 & $1,3-34: 2 ; 16: 0 / 18: 2$ & $\begin{array}{l}\mathrm{MS}^{2} \text { 610: } 575^{\mathrm{i}}, \mathrm{MS}^{2} 575: 263^{\mathrm{k}} \\
239^{\mathrm{k}}\end{array}$ & $3.7 \pm 0.01 ; 0.96$ \\
\hline & 55.0 & $1,2-34: 2 ; 16: 0 / 18: 2$ & $\mathrm{MS}^{2} 610: 575^{\mathrm{i}} 337^{\mathrm{e}}, 313^{\mathrm{e}}$ & \\
\hline 612.7 & 51.3 & $1,3-34: 1 ; 16: 0 / 18: 1$ & $\mathrm{MS}^{2} 577: 265^{\mathrm{k}}, 239^{\mathrm{k}}$ & \\
\hline \multirow{4}{*}{630.7} & 54.6 & $1,2-34: 1 ; 16: 0 / 18: 1$ & $\mathrm{MS}^{2}$ 612: n.r. & $2.9 \pm 0.05 ; 1.09$ \\
\hline & 52.2 & $1,3-36: 6$ & $\mathrm{MS}^{2} 630: 613^{\mathrm{d}}, 595^{\mathrm{i}}$ & \\
\hline & 55.8 & $1,2-36: 6 ; 18: 3 / 18: 3$ & $\begin{array}{l}\operatorname{MS}^{2} 630: 613^{\mathrm{d}}, 595^{\mathrm{i}}, 333^{\mathrm{e}}, 335^{\mathrm{e}}, \\
337^{\mathrm{e}}\end{array}$ & $0.5 \pm 0.02 ; 0.85$ \\
\hline & & $18: 2 / 18: 4$ & & \\
\hline \multirow[t]{2}{*}{632.7} & 52.0 & $1,3-36: 5 ; 18: 2 / 18: 3$ & $\mathrm{MS}^{2} 632: 615^{\mathrm{d}}, 597^{\mathrm{i}}, 335^{\mathrm{e}}$ & $4.9 \pm 0.22 ; 0.90$ \\
\hline & 55.4 & $1,2-36: 5 ; 18: 2 / 18: 3$ & $\mathrm{MS}^{2} 632: 615^{\mathrm{d}}, 597^{\mathrm{i}}, 335^{\mathrm{e}}, 337^{\mathrm{e}}$ & \\
\hline \multirow[t]{2}{*}{634.8} & 51.6 & $1,3-36: 4 ; 18: 2 / 18: 2$ & $\begin{array}{l}\mathrm{MS}^{2} 634: 617^{\mathrm{d}}, 599^{\mathrm{i}}, \mathrm{MS}^{2} 599: \\
261^{\mathrm{k}}, 263^{\mathrm{k}}, 265^{\mathrm{k}}\end{array}$ & $19.1 \pm 0.24 ; 1.00$ \\
\hline & 55.0 & $1,2-36: 4 ; 18: 2 / 18: 2$ & $\mathrm{MS}^{2} 634: 617^{\mathrm{d}}, 335^{\mathrm{e}}, 337^{\mathrm{e}}, 339^{\mathrm{e}}$ & \\
\hline \multirow[t]{2}{*}{636.9} & 51.4 & $1,3-36: 3 ; 18: 1 / 18: 2$ & $\begin{array}{l}\mathrm{MS}^{2} \text { 636: } 601^{\mathrm{i}}, \mathrm{MS}^{2} 601: 263^{\mathrm{k}} \\
265^{\mathrm{k}}\end{array}$ & $26.9 \pm 0.21 ; 1.03$ \\
\hline & 54.6 & $1,2-36: 3 ; 18: 1 / 18: 2$ & $\mathrm{MS}^{2}$ 636: $619^{\mathrm{d}}, 601^{\mathrm{i}}, 337^{\mathrm{e}}, 339^{\mathrm{e}}$ & \\
\hline \multirow[t]{2}{*}{638.8} & 51.1 & $1,3-36: 2 ; 18: 1 / 18: 1$ & $\mathrm{MS}^{2}$ 638: $603^{\mathrm{i}}, \mathrm{MS}^{2}$ 603: $265^{\mathrm{k}}$ & $34.0 \pm 1.02 ; 1.20$ \\
\hline & 54.3 & $1,2-36: 2 ; 18: 1 / 18: 1$ & $\mathrm{MS}^{2} 638: 621^{\mathrm{d}}, 603^{\mathrm{i}}, 339^{\mathrm{e}}$ & \\
\hline \multirow[t]{2}{*}{640.8} & 51.1 & $1,3-36: 1 ; 18: 0 / 18: 1$ & $\mathrm{MS}^{2}$ 640:, $\mathrm{MS}^{2} 605^{\mathrm{i}}: 265^{\mathrm{k}}$ & $5.7 \pm 0.44 ; 1.48$ \\
\hline & 54.2 & $1,2-36: 1 ; 18: 0 / 18: 1$ & $\mathrm{MS}^{2}$ 640: $623^{\mathrm{d}}, 605^{\mathrm{i}}, 339^{\mathrm{e}}, 341^{\mathrm{e}}$ & \\
\hline \multirow[t]{2}{*}{666.7} & 50.9 & $1,3-38: 2$ & $\mathrm{MS}^{2}$ 666: n.r. & $1.0 \pm 0.11 ; 1.32$ \\
\hline & 54.1 & $1,2-36: 2$ & $\mathrm{MS}^{2}$ 666: n.r. & \\
\hline
\end{tabular}


Table 8 (Continued)

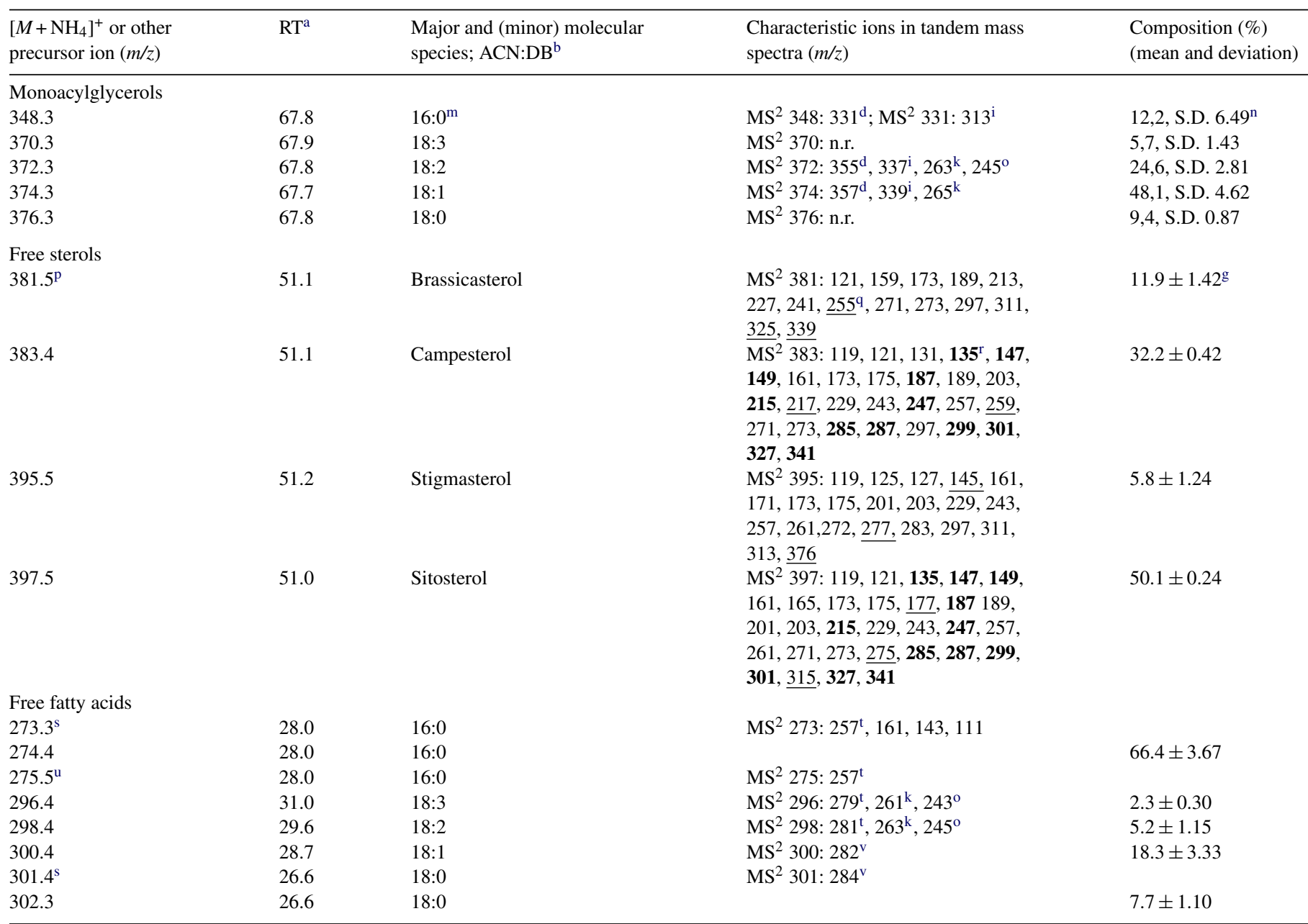

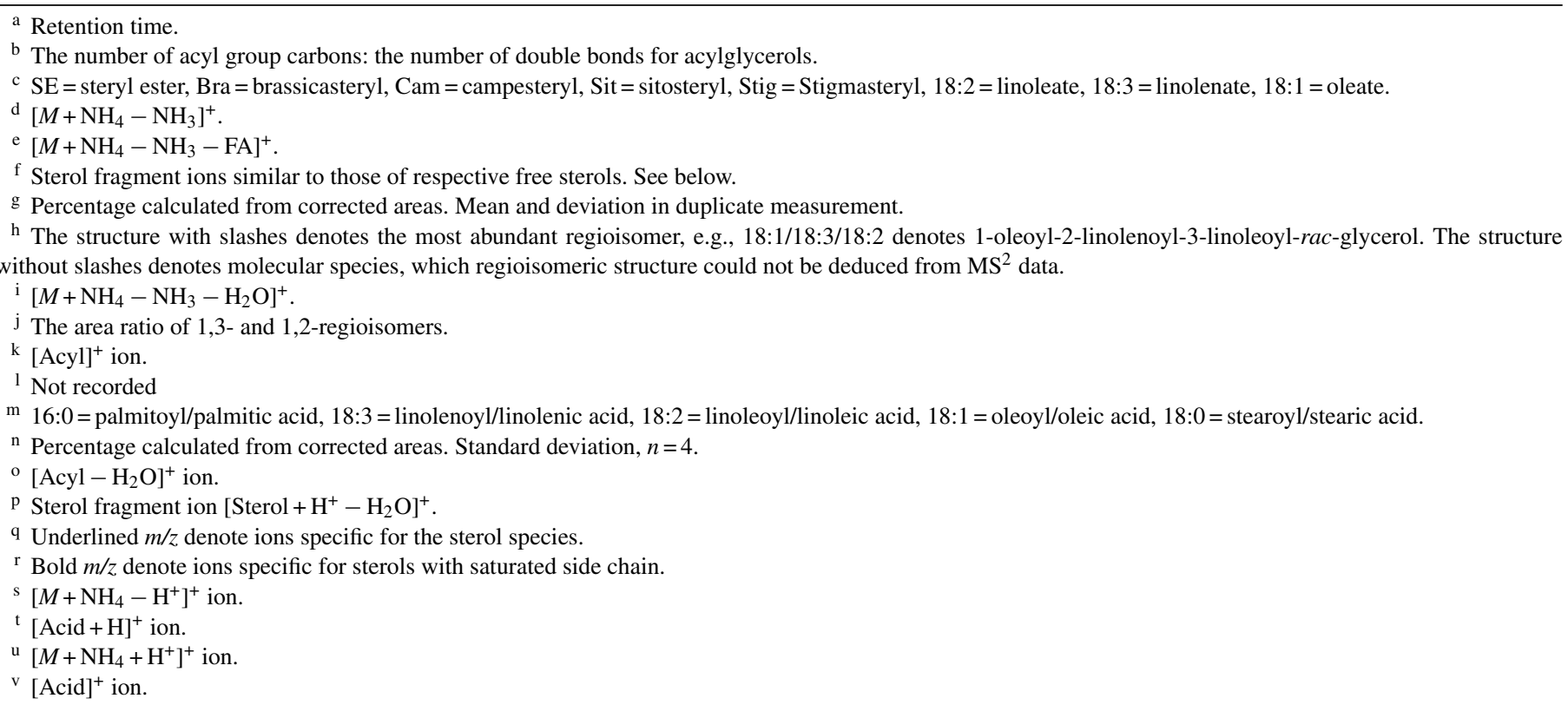

The mechanism shown in Scheme 1, differs from those presented by Duffin et al. [2], Cheng et al. [3], and McAnoy et al. [9]. However, the stepwise mechanism presented here is consistent with the $\mathrm{MS}^{2}$ and $\mathrm{MS}^{3}$ data of labeled TAGs
[9], which indicate that $\alpha$-methylene and the hydrogen atoms of glycerol are not involved in the loss of carboxylic acid but the hydrogen atoms of ammonium ion. Furthermore, our FI-MS ${ }^{3}\left[M+\mathrm{NH}_{4}\right]^{+} \rightarrow\left[\left(M+\mathrm{NH}_{4}\right)-\mathrm{NH}_{3}-\mathrm{FA}\right]^{+}$data indi- 
cated, unlike Duffin et al. [2] and Cheng et al. [3], but in agreement with Marzilli et al. [6] and McAnoy et al. [9] that [Acyl] ${ }^{+}$ ions are formed from the DAG ion $\left[\left(M+\mathrm{NH}_{4}\right)-\mathrm{NH}_{3}-\mathrm{FA}\right]^{+}$, not directly from $\left[M+\mathrm{NH}_{4}\right]^{+}$. Furthermore, our data showed that $[\text { Acyl }+74]^{+}$and $\left[\left(M+\mathrm{NH}_{4}\right)-\mathrm{NH}_{3}-\mathrm{FA}-74\right]^{+}$are formed from DAG ion $\left[\left(M+\mathrm{NH}_{4}\right)-\mathrm{NH}_{3}-\mathrm{FA}\right]^{+}$in accordance with data published elsewhere $[3,6,9]$.

\section{Diacylglycerols (DAGs)}

To our knowledge, mass spectrometric differention of regioisomers of intact DAGs have not been reported previously. Duffin et al. [2] acquired at $130 \mathrm{eV}$ collision energy the $\mathrm{MS}^{2}$ spectrum of ammonium adduct of dipalmitin, which was produced in the presence of $10 \mathrm{mM}$ ammonium acetate. The $\mathrm{MS}^{2}$ spectrum showed in addition to $\left[M+\mathrm{NH}_{4}-\mathrm{NH}_{3}-\mathrm{H}_{2} \mathrm{O}\right]^{+}$ion $\left[M+\mathrm{NH}_{4}-\mathrm{NH}_{3}-\mathrm{FA}\right]^{+}$and $[\text {Acyl }]^{+}$ions, thus differing from the $\mathrm{MS}^{2}$ spectra of 1,3-dipalmitin, 1,3- and 1,2-diolein recorded in this study under different conditions. APCI LC-MS has been applied to identification of DAGs [14-16,30], but no regiospecific information was obtained. Positive ESI-FT-ICR-MS provided ACN:DB fingerprints of DAGs [13] and MALDI time of flight MS only protonated sodium and potassium adducts [17], and thus no information on esterified FAs nor regioisomers.

In the present study, ammonium ions in the presence of ammonia made available soft ionization conditions, which probably led to different fragmentation paths for 1,3- and 1,2-DAGs (Scheme $2 \mathrm{a}$ and $\mathrm{b}$ ) and thus permitted mass spectrometric identification of regioisomers. Fragmentation seemed to be sensitive to the changes in the analytical conditions, as shown by the $\mathrm{MS}^{2}$ data of 1,3-dihexadecanoylglycerol: under similar mass spectrometric conditions, $\mathrm{MS}^{2}\left[M+\mathrm{NH}_{4}\right]^{+}$produced in the LC-MS and FI mode $100 \%$ peaks of $\left[\left(M+\mathrm{NH}_{4}\right)-\mathrm{NH}_{3}\right]^{+}$and $\left[\left(M+\mathrm{NH}_{4}\right)-\mathrm{NH}_{3}-\mathrm{H}_{2} \mathrm{O}\right]^{+}$ions, respectively (Table 3$)$.

The presence of $\left[M+\mathrm{NH}_{4}-\mathrm{NH}_{3}\right]^{+}$ions with variable abundance, in the $\mathrm{MS}^{2}\left[M+\mathrm{NH}_{4}\right]^{+}$of 1,3- and 1,2-DAGs indicated the stepwise fragmentation mechanisms (Scheme 2a and b). However, a strong evidence by $\mathrm{MS}^{3}\left[M+\mathrm{NH}_{4}\right]^{+}$ $\rightarrow\left[\left(M+\mathrm{NH}_{4}\right)-\mathrm{NH}_{3}\right]^{+}$for the second fragmentation step of DAGs could not be presented as shown for TAGs and MAGs. The third step of fragmentation of 1,3-DAGs is evident from FI-MS ${ }^{3}$ $\left[M+\mathrm{NH}_{4}\right]^{+} \rightarrow\left[M+\mathrm{NH}_{4}-\mathrm{NH}_{3}-\mathrm{H}_{2} \mathrm{O}\right]^{+}$. The second step of fragmentation of 1,2-DAGs is consistent with $\mathrm{MS}^{2}\left[M+\mathrm{NH}_{4}\right]^{+}$.

\section{Monoacylglycerols (MAGs)}

Duffin et al. [2] recorded ESI-MS ${ }^{2}$ of monopalmitin under the same conditions described for dipalmitin. The spectrum showed $\left[M+\mathrm{NH}_{4}-\mathrm{NH}_{3}\right]^{+},\left[\left(M+\mathrm{NH}_{4}\right)-\mathrm{NH}_{3}-\mathrm{H}_{2} \mathrm{O}\right]^{+}$, and $[\text { Acyl }]^{+}$ions. In the present study, the $\mathrm{MS}^{2}\left[M+\mathrm{NH}_{4}\right]^{+}$, FI-MS ${ }^{3}\left[M+\mathrm{NH}_{4}\right]^{+} \rightarrow\left[\left(M+\mathrm{NH}_{4}\right)-\mathrm{NH}_{3}\right]^{+}$, and FI-MS ${ }^{3}$ $\left[M+\mathrm{NH}_{4}\right]^{+} \rightarrow\left[\left(M+\mathrm{NH}_{4}\right)-\mathrm{NH}_{3}-\mathrm{H}_{2} \mathrm{O}\right]^{+}$, provided distinct evidence for the proposed stepwise mechanism (Scheme 3). In the MS of unsaturated MAGs, the ammonium adduct ion was the base peak and the $\left[M+\mathrm{NH}_{4}-\mathrm{NH}_{3}\right]^{+}$ion was a medium abundance peak, whereas the $\mathrm{MS}^{2}\left[M+\mathrm{NH}_{4}\right]^{+}$showed low-to-high abundance $[\text { Acyl }]^{+}$, low-to-medium abundance $\left[\text {Acyl }-\mathrm{H}_{2} \mathrm{O}\right]^{+}$,

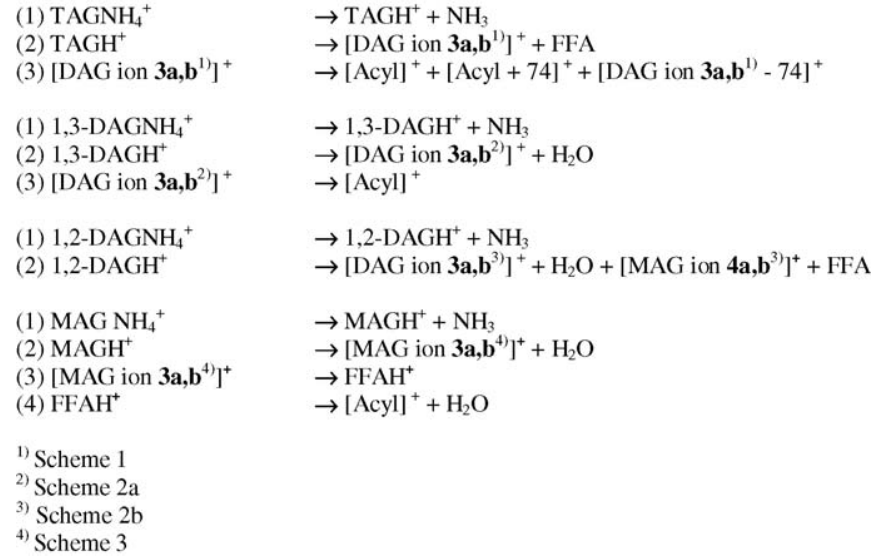

Scheme 5 .

and low abundance $[\text { Acid }+\mathrm{H}]^{+}$ions. In the MS of saturated MAGs both $\left[M+\mathrm{NH}_{4}\right]^{+}$and $\left[M+\mathrm{NH}_{4}-\mathrm{NH}_{3}\right]^{+}$were abundant but the intensity ratio of the former to the latter decreased as the chain length decreased; in addition the $\mathrm{MS}^{2}$ $\left[M+\mathrm{NH}_{4}\right]^{+}$showed abundant $\left[M+\mathrm{NH}_{4}-\mathrm{NH}_{3}\right]^{+}$and low-tomedium abundance $\left[\left(M+\mathrm{NH}_{4}\right)-\mathrm{NH}_{3}-\mathrm{H}_{2} \mathrm{O}\right]^{+}$ions. Therefore, $\mathrm{MS}^{2}\left[M+\mathrm{NH}_{4}\right]^{+}$, which can be recorded in auto-MS/MS mode, of unsaturated MAGs provided more acyl-specific information than that of saturated MAGs. However, owing to the presence of one acyl group per MAG molecule $\left[M+\mathrm{NH}_{4}-\mathrm{NH}_{3}\right]^{+}$ and $\left[\left(M+\mathrm{NH}_{4}\right)-\mathrm{NH}_{3}-\mathrm{H}_{2} \mathrm{O}\right]^{+}$ions in the $\mathrm{MS}^{2}\left[M+\mathrm{NH}_{4}\right]^{+}$ gave relatively reliable evidence for the $\mathrm{ACN}$ of saturated MAGs.

\section{Fragmentation paths of acylglycerols (TAGs,DAGs,} and MAGs)

The MS data presented for ammonium adducts of TAGs, DAGs, and MAGs exhibited similarity in their fragmentation paths (Scheme 5). In the first step (1), the ammonium ion of the ammonium adduct donates a proton to acylglycerol, and ammonia is concomitantly released. In the second step (2), FFA is cleaved from protonated TAG, water from protonated 1,3-DAG and MAG, both FFA and water from protonated 1,2-DAG, thus leading to formation of $[\mathrm{DAG}]^{+}$ion from TAG and 1,3-DAG, $[\mathrm{DAG}]^{+}$ion and $[\mathrm{MAG}]^{+}$ion from 1,2-DAG, and $[\mathrm{MAG}]^{+}$ion from MAG. In the third step (3), [DAG $]^{+}$ion of TAG is fragmented to yield $[\text { Acyl }]^{+},[\text {Acyl }+74]^{+},[\text {DAG ion }-74]^{+}$ions, [DAG] ion of 1,3 DAG to [Acyl] ${ }^{+}$ions, and $[\mathrm{MAG}]^{+}$ion of MAG to protonated FA, which is decomposed to water and [Acyl] ${ }^{+}$ ions, in the fourth step (4).

\section{Sterol esters and free sterols (SEsandSs)}

Lusby et al. [20] observed in the GC-EI-MS of sterol esters following characteristic ions: $[M-\mathrm{RCOO}]^{+},[M-\mathrm{RCOOH}]^{+}$, $\left[M-\mathrm{RCOOH}-\mathrm{CH}_{3}\right]^{+},[M-\mathrm{RCOOH}-\text { side chain }]^{+},[M-$ $\mathrm{RCOOH}-$ side chain $-2 \mathrm{H}]^{+}, \quad[M-\mathrm{RCOOH}-$ side chain $-42]^{+}$. The MS data presented showed that the $m / z$ values and (relative abundance in percentage) of above fragments for 
sitosteryl linoleate were 397(36), 396(58), 381(6), 255(12), 253(1), 213(13), respectively, and for campesteryl linolenate 383(37), 382(51), 367(5), 255(11), 253(0), 213(10), respectively. The characteristic ions with the same $\mathrm{m} / \mathrm{z}$ values are present among others in the EI-MS of sitosterol and campesterol trimethylsilyl ethers [33].

The present ESI-MS data were similar to the EI-MS data to some extent. The $\mathrm{MS}^{2}\left[M+\mathrm{NH}_{4}\right]^{+}$of SEs showed $\left[M+\mathrm{NH}_{4}-\mathrm{NH}_{3}-\mathrm{FA}\right]^{+}$ions (characteristic sterol fragment ions), which have the same $\mathrm{m} / \mathrm{z}$ values as the $\left[M-\mathrm{RCOO}^{+}\right.$ ions in EI MS (Table 8). The $\mathrm{MS}^{2}\left[M+\mathrm{NH}_{4}-\mathrm{NH}_{3}-\mathrm{FA}\right]^{+}$of sterol esters and the $\mathrm{MS}^{2}$ of [characteristic sterol fragment ${ }^{+}$ ions of Ss showed further fragment ions of $\mathrm{m} / \mathrm{z}$ series with increment of 14 mass units, which are formed in the fragmentation of side chain. For example, $\mathrm{MS}^{2}\left[M+\mathrm{NH}_{4}-\mathrm{NH}_{3}-\mathrm{FA}\right]^{+}$ of sitosterol esters or sitosterol fragment ion of free sitosterol showed two series: $m / z 341,327,-, 299,285,271$, and 315 , $301,287,273$. In the $\mathrm{MS}^{2}\left[M+\mathrm{NH}_{4}-\mathrm{NH}_{3}-\mathrm{FA}\right]^{+}$of sitosterol, campesterol and stigmasterol esters, and in those of respective ions of $\mathrm{Ss},\left[M-\mathrm{NH}_{3}-\mathrm{FA}-\text { side chain }\right]^{+}$ion is the ion with $\mathrm{m} / \mathrm{z}, 257$ and the fragments of sterol nucleus are ions with $\mathrm{m} / z$ 243, 229, 215, 201, 187, and 173. In the EI MS of sitosterol and campesterol trimethylsilyl ethers, the ion formed by cleavage of side chain is ion with $\mathrm{m} / \mathrm{z} 255$, and further fragment of sterol nucleus is $[M-\mathrm{RCOOH}-\text { side chain }-42]^{+}$ ion with $m / z 213$ [33]. In the $\mathrm{MS}^{2}\left[M+\mathrm{NH}_{4}-\mathrm{NH}_{3}-\mathrm{FA}\right]^{+}$ of brassicasterol esters and in those of respective ion of free brassicasterol, $\left[M+\mathrm{NH}_{4}-\mathrm{NH}_{3}-\mathrm{FA}-\text { side chain }-2 \mathrm{H}\right]^{+}$ion with $m / z 255$ instead of [ $M-\mathrm{NH}_{3}-\mathrm{FA}-$ side chain $]^{+}$ion was observed, along with fragments of sterol nucleus $m / z 241,227$, 213 (Table 8).

\section{Free fatty acids (FFAs)}

Kerwin et al. [23] used low-energy NI-ESI-MS and -MS ${ }^{2}$ to characterize saturated and unsaturated FFAs. Han et al. [11] determined FFA anions in two-dimensional ESI-MS by comparison of their intensities with that of internal standard. Carrier and Parent [26] used RP-LC-NI-ESI-MS to quantify FFAs in phospholipid based formulations, whereas Perret et al. [27] used RP-LC-NI-ESI-MS and -MS ${ }^{2}$ to determine and identify FFAs in chocolate samples. Hsu and Turk [25] studied dilithiated adducts of long-chain unsaturated FFAs using positive ion ESI-MS and -MS ${ }^{2}$. The $\mathrm{MS}^{2}$ in the studies $[23,25,27]$ could be used for the localization of double bonds in unsaturated FFAs. The applicability of NP-LC with positive ion ESI-MS and -MS ${ }^{2}$ of $\left[M+\mathrm{NH}_{4}\right]^{+}$(or $\left[M+\mathrm{NH}_{4}-\mathrm{H}\right]^{+}$) ions for identification and quantification of FFAs has apparently not been presented previously. However, our data did not convey any information on the location of double bonds in unsaturated FFAs. The $\mathrm{MS}^{3}$ and $\mathrm{MS}^{2}$ of unsaturated FFA indicated clearly the stepwise fragmentation mechanism (Scheme 4).

\section{Analysis of low erucic acid rapeseed oil}

In our study, 23 molecular species in $17 \mathrm{ACN}$ :DB classes of TAGs could be identified. This is less than identified by NI-
CI-MS/MS [29] and by APCI-MS [30,31,15]. Low intensity $\left[M+\mathrm{NH}_{4}\right]^{+}$ions for ACN classes 50, 56, and 58 of TAGs were detected, but the additional recordings required for identification of molecular species of these classes were not pursued. In the CID of the $\left[M+\mathrm{NH}_{4}\right]^{+}$ions of triacid TAGs, the relative abundance of $\left[\left(M+\mathrm{NH}_{4}\right)-\mathrm{NH}_{3}-s n-2 \mathrm{FA}\right]^{+}$ions varied in the range $21-28 \%$. This is a high range relative to the respective relative abundance of 1-lauroyl-2-oleoyl-3-palmitoyl-rac-glycerol $(17 \%)$, which indicates that molecular species of low erucic acid rapeseed oil TAGs are in fact mixtures of regioisomers. However, the dominant regioisomer can be deduced from relative abundance data. In the dominant regioisomers, palmitic and stearic acids were esterified predominantly (96 and 93\%, respectively) in the $s n$-1(3) position (Table 8), which agrees with the stereospecific distribution of saturated FAs in vegetable oils [34]. Furthermore, this is in agreement with the high proportion of palmitic and stearic acids among FFAs, which may be released from these positions via hydrolysis by 1,3-specific lipases. The five predominating regioisomers in the present study was consistent with those in two studies using APCI-MS [30,15]. Furthermore, the identification of two and four regioisomers in this study was the same as in the studies [30] and [15], respectively. The identity of four regioisomers was the same in the studies of Mottram et al. [30] and Holčapek et al. [15], but different from that observed in our study. Recall that, in order to deduce the identity of a regioisomer from MS recorded by LC-APCI-MS, the molecular species has to be chromatographically separated from the molecular species of other ACN:DB classes. In the ESI-MS this is not required, because the regioisomer is deduced from CID of isolated $\left[M+\mathrm{NH}_{4}\right]^{+}$ion.

Byrdwell et al. [31] quantified rapeseed (Canola) oil TAGs using APCI-MS and response factors calculated from FA\% ratios determined by GC-FID and APCI-MS. Holčapek et al. [15] identified regioisomers of rapeseed oil TAGs from APCIMS, and quantified the TAG species on the basis of the relative peak areas measured with UV detection. There is a relatively good agreement of the proportions of major and minor molecular species between our study and the aforementioned two studies.

Mottram et al. [30] identified eight molecular species of DAGs in low erucic acid rapeseed oil by APCI-MS, whereas Holčapek et al. identified only five [15], but no data pertaining to regioisomers nor quantitative estimation of molecular species of DAGs were presented in either study. In the present study, the sum of regioisomers of DAGs and their area ratios was calculated. If standards with known regioisomer ratio would be available for calibration, the real ratios of regioisomers could be measured by the present method. To our knowledge, this is the first mass spectrometric determination of MAGs.

In the present study the SE composition (\%) was calculated. In order to compare the present data to the data obtained by precursor ion $\mathrm{MS}^{2}$ and GLC of transesterified isolated SE fraction [19], the compostions of esterified Ss and esterified FAs were calculated. A relatively good consistency in terms of S's composition was obtained between the present study (\%), that determined by precursor ion $\mathrm{MS}^{2}$ (mol\%) [19], and that determined by GLC (mol\%) [19], as apparent from the values pertaining to brassicasterol esters $(5.7,3.49$, and 4.96 , respec- 
tively), campesterol esters $(46.3,44.61$, and 43.67 , respectively), stigmasterol esters (1.6, 2.31, and-, respectively), and sitosterol esters $(46.5,49.14$, and 53.8, respectively).

The composition (\%) of Ss calculated from corrected areas of characteristic $\mathrm{S}$ fragment ions $\mathrm{m} / \mathrm{z} 381,383,395$, and 397 agreed well with the composition (mol\%) determined by (GLC) [19], as apparent from the values pertaining to brassicasterol (11.9 and 12.19 , respectively), campesterol (32.2 and 32.98, respectively), stigmasterol (5.8 and 1.00, respectively), and sitosterol (50.1 and 53.82 , respectively).

The deviations of duplicate measurements of SE, TAG, DAG, and $\mathrm{S}$ were relatively small and varied for the most abundant species (i.e., $>10 \%$ ) in these lipid classes (and for the least abundant species) (i.e., $<10 \%)$ between $0.4-2.5(0.3-10)$, $0.3-5(0.3-10), 0.8-3(0.3-11)$, and $0.5-12(21) \%$, respectively (Table 8 ). The deviations of MAGs and FFAS were higher: the relative standard deviations of MAGs varied between 9 and $53 \%$, and the deviation of duplicate measurements of FFAs varied in the range $6-22 \%$.

\section{Significance of the results}

The knowledge of fragmentation pathways plays a central role in mass spectrometry, and is required for correct interpretation of MS data besides being crucial for development of analytical method. In order to test the applicability of the MS and $\mathrm{MS}^{2}$ data for identification and quantification of components of simple lipid classes, the methodologies developed were applied in analysis of simple lipid classes in low erucic acid rapeseed oil. Comprehensive qualitative and quantitative data of that oil were thus obtained, but such methods are in principle applicable to similar analysis of any extracts of biological samples. Note that the application of internal standardization will provide absolute concentrations. Comprehensive data on molecular species in intact simple lipids, relative to the data obtained by conventional, indirect methods, are more appropriate for evaluation of nutritional and metabolic effects of lipid class components and the effects on technical properties of oils.

\section{Acknowledgement}

Financial support for João M. Rocha was provided by a Ph.D. fellowship (PRAXIS XXI/BD/16060/98) within program PRAXIS XXI, administered by FCT (Portugal).

\section{References}

[1] W.W. Christie, Gas Chromatography and Lipids: A Practical Guide, The Oily Press, Glasgow, 1989, p. 11.

[2] K.L. Duffin, J.D. Henion, J.J. Shieh, Anal. Chem. 63 (1991) 1781.

[3] C. Cheng, M.L. Gross, E. Pittenauer, Anal. Chem. 70 (1998) 4417.

[4] E. Hvattum, Rapid Commun. Mass Spectrom. 15 (2001) 187.

[5] C.A. Dorschel, J. Am. Oil Chem. Soc. 79 (2002) 749.

[6] L.A. Marzilli, L.B. Fay, F. Dionisi, P. Vouros, J. Am. Oil Chem. Soc. $80(2003) 195$.

[7] P. Kalo, A. Kemppinen, V. Ollilainen, A. Kuksis, Int. J. Mass Spectrom. 229 (2003) 167.

[8] P. Kalo, A. Kemppinen, V. Ollilainen, A. Kuksis, Lipids 39 (2004) 915.

[9] A.M. McAnoy, C.C. Wu, R.C. Murphy, J. Am. Soc. Mass Spectrom. 16 (2005) 1498.

[10] F.-F. Hsu, J. Turk, J. Am. Soc. Mass Spectrom. 10 (1999) 587.

[11] X. Han, J. Yang, H. Cheng, H. Ye, R.W. Gross, Anal. Biochem. 330 (2004) 317.

[12] S.D. Segall, W.E. Artz, D.S. Raslan, V.P. Ferraz, J.A. Takahashi, J. Am. Oil Chem. Soc. 81 (2004) 143.

[13] Z. Wu, R.P. Rodgers, A.G. Marshall, J. Agric. Food Chem. 52 (2004) 5322.

[14] H. Mu, H. Sillen, C.-E. Hoy, J. Am. Oil Chem. Soc. 77 (2000) 1049.

[15] M. Holčapek, P. Jandera, P. Zderadička, L. Hrubá, J. Chromatogr. A 1010 (2003) 195.

[16] K. Nagy, D. Bongiorno, G. Avellone, P. Agozzino, L. Ceraulo, K. Vékey, J. Chromatogr. A 1078 (2005) 90.

[17] J. Schiller, J. Arnold, S. Bernard, M. Müller, S. Reichl, K. Arnold, Anal. Biochem. 267 (1999) 46.

[18] K. Duffin, M. Obukowicz, A. Raz, J.J. Shieh, Anal. Biochem. 279 (2000) 179.

[19] P. Kalo, T. Kuuranne, J. Chromatogr. A 935 (2001) 237.

[20] W.R. Lusby, M.J. Thomson, J. Kochansky, Lipids 19 (1984) 888.

[21] L. Dyas, M.C. Precott, R.P. Evershed, L.J. Goad, Lipids 26 (1991) 536.

[22] N. Fang, S. Yu, T.M. Badger, J. Agric. Food Chem. 51 (2003) 3260.

[23] J.L. Kerwin, A.M. Wiens, L.H. Ericsson, J. Mass Spectrom. 31 (1996) 184.

[24] P. Wheelan, J.A. Zirroli, R.C. Murphy, J. Am. Soc. Mass Spectrom. 7 (1996) 140.

[25] F.-F. Hsu, J. Turk, J. Am. Soc. Mass Spectrom. 10 (1999) 600.

[26] A. Carrier, J. Parent, J. Liquid Chromatogr. Rel. Technol. 24 (2001) 97.

[27] D. Perret, A. Gentili, S. Marchese, M. Sergei, L. Caporossi, Rapid Commun. Mass Spectrom. 18 (2004) 1989.

[28] T. Murata, Anal. Chem. 49 (1977) 2209.

[29] H. Kallio, G. Currie, Lipids 28 (1993) 207.

[30] H.R. Mottram, S.E. Woodbury, R.P. Evershed, Rapid Commun. Mass Spectrom. 11 (1997) 1240.

[31] W.C. Byrdwell, W.E. Neff, G.R. List, J. Agric. Food Chem. 49 (2001) 446.

[32] W.M. Lauer, A.J. Aasen, G. Graff, R.T. Holman, Lipids 5 (1970) 861.

[33] P.C. Dutta, L. Normen, J. Chromatogr. A 816 (1998) 177.

[34] F.B. Padley, F.D. Gunstone, J.L. Harwood, in: F.D. Gunstone, J.L. Harwood, F.B. Padley (Eds.), The Lipid Handbook, Chapman and Hall, Great Britain, 1994, p. 123. 